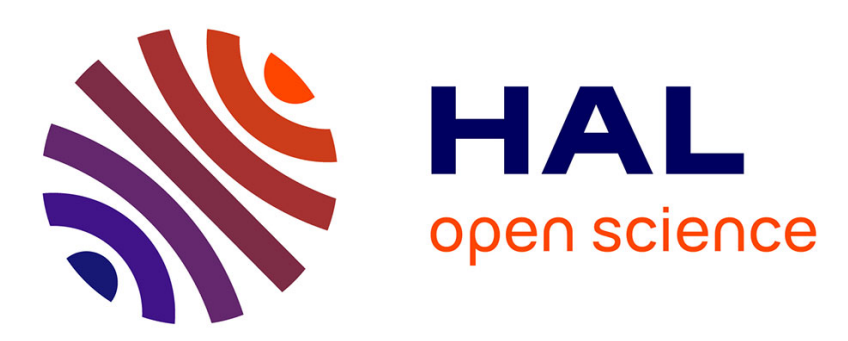

\title{
A new algorithm for computing the indentation of a rigid body of arbitrary shape on a viscoelastic half-space
}

Ivan Kozhevnikov, Denis Duhamel, Honoré P. Yin, Julien Cesbron, Fabienne Anfosso-Lédée

\section{- To cite this version:}

Ivan Kozhevnikov, Denis Duhamel, Honoré P. Yin, Julien Cesbron, Fabienne Anfosso-Lédée. A new algorithm for computing the indentation of a rigid body of arbitrary shape on a viscoelastic half-space. International Journal of Mechanical Sciences, 2008, 50 (7), pp.1194-1202. 10.1016/j.ijmecsci.2008.04.003 . hal-00309050

\section{HAL Id: hal-00309050 https://hal.science/hal-00309050}

Submitted on 6 Aug 2008

HAL is a multi-disciplinary open access archive for the deposit and dissemination of scientific research documents, whether they are published or not. The documents may come from teaching and research institutions in France or abroad, or from public or private research centers.
L'archive ouverte pluridisciplinaire HAL, est destinée au dépôt et à la diffusion de documents scientifiques de niveau recherche, publiés ou non, émanant des établissements d'enseignement et de recherche français ou étrangers, des laboratoires publics ou privés. 


\title{
A new algorithm for computing the indentation of a rigid body of arbitrary shape on a viscoelastic half-space
}

\author{
I.F. Kozhevnikov ${ }^{\text {a,* }}$, D. Duhamel ${ }^{\text {a }}$, H.P. Yin ${ }^{\mathrm{a}, *}$, J. Cesbron ${ }^{\mathrm{b}}$, \\ F. Anfosso-Lédée ${ }^{\mathrm{b}}$, \\ ${ }^{a}$ Université Paris-Est, Institut Navier, ENPC, 6-8 Av. Blaise Pascal, 77455 \\ Marne la Vallée, Cedex 2, France \\ ${ }^{\mathrm{b}} L C P C, B P$ 4129, 44341 Bouguenais Cedex, France
}

\begin{abstract}
In this paper the contact problem between a rigid indenter of arbitrary shape and a viscoelastic half-space is considered. Under the action of a normal force the penetration of the indenter and the distribution of contact pressure change. We wish to find the relations which link the pressure distribution, the resultant force on the indenter and the penetration on the assumption that the surfaces are frictionless. For indenters of arbitrary shape the problem may be solved numerically by using the Matrix Inversion Method (MIM), extended to viscoelastic case. In this method the boundary conditions are satisfied exactly at specified "matching points" (the mid-points of the boundary elements). It can be validated by comparing the numerical results to the analytic solutions in cases of a spherical asperity (loading and unloading) and a conical asperity (loading only).
\end{abstract}

Key words: Contact mechanics, Viscoelastic contact, Viscoelasticity, Indenter, 


\section{Introduction}

Many contact problems are influenced by the viscoelastic behaviour of the materials. This influence is difficult to be analysed for practical problems. For example, the contact between a tyre and a road is mainly modelled in the frame of the elastic theory. The viscoelastic effects have not been taken into account for computing the pressure distribution. In fact the dynamic modulus of rubber is frequency dependent and more important than the elastic modulus. The aim of our work is to compare the viscoelastic model to the elastic model for a single asperity of arbitrary shape for a increasing and then decreasing vertical loading.

The normal contact between a perfectly rigid indenter and a plane elastic halfspace was first investigated by Boussinesq [1] using the potential theory. Hertz $[2,3]$ also gave an analytical solution of the contact problem in the case of two elastic bodies with smooth and quadratic contacting surfaces. Numerous analytical or semi-analytical solutions were then derived from Boussinesq's theory for a rigid indenter of arbitrary shape on an elastic half-space, especially in axisymmetric contact cases by Sneddon [4]. The paper of Gauthier et al. [5] is concerned with the indentation of an elastic half-space by an axisymmetric indenter under a monotonically applied normal force and under the assumption

* Corresponding author : Tel: 33 (0)1 641537 25; Fax: 33 (0)1 64153741

Email addresses: vano1979@online.ru (I.F. Kozhevnikov), yin@lami.enpc.fr (H.P. Yin). 
of Coulomb friction in the region of contact.

The problem of a rigid indenter pressed into contact with a viscoelastic solid was also investigated by many authors. The simplest approach to this problem follows a suggestion by Radok [6] for finding the stresses and deformations in cases where the corresponding solution for an elastic material is known. It consists in replacing the elastic constant in the elastic solution by the corresponding integral operator from the viscoelastic stress-strain relations. This approach can be applied to the contact problem provided that the loading program is such that the contact area is increasing. Radok's technique breaks when the contact area decreases. This complication has been studied by Ting [7] for a rigid axisymmetric indenter. Recently Vandamme and Ulm [8] show that for conical indenter suggestion of Radok remains valid at the very beginning of the unloading phase as well.

Analytical, numerical and experimental studies have been made in case of spherical, conical, pyramid indenters. Ball (Brinell) and flat (Boussinesq) punch indentation was analysed theoretically in the work of Larsson and Carlsson [9]. The elliptic indenter has been investigated by Yang [10]. The sharp indentation tests (the standard shapes of the Vickers, Berkovich and Knoop pyramids) are frequently used to examine hard materials like ceramics. The advantage of these tests is the simplicity of the experimental procedure. The work of Giannakopoulos [11] presents the results of frictionless and adhesionless contact of flat surfaces by pyramid indenters. One can also note the numerical works $\mathrm{Mu}-$ rakami et al. [12], Larsson et al. [13] for the analysis of Berkovich indentation; the works of Rabinovich and Savin [14] - for the analysis of Knoop indentation. Cheng et al. [15] analyse the indentation of viscoelastic solids by a sphericaltip indenter. Their solutions can apply to the response of compressible as well 
as incompressible coated layers to a spherical-tip indentation.

In this paper we propose a new algorithm for computing the indentation of a rigid body of arbitrary shape on a viscoelastic half-space. The Matrix Inversion Method (Kalker [16]) which is described in the book of Johnson [17] is used in $[18,19]$ for the analysis of the elastic tyre-road contact. We are extending this method to the viscoelastic problem to compute the pressure distribution history for any load or penetration history.

The paper is structured as follows. The indentation by a rigid indenter of arbitrary shape will be considered first. Then the discretization of the contact problem will be made. Next it will be possible to solve the general contact problem by the Matrix Inversion Method (MIM). The general methodology will be applied to the spherical, conical and cylindrical indenters. The MIM will be compared first to the analytical results for a single spherical indenter (loading and unloading) and secondly to the analytical results for a single conical indenter (loading only). Then the indentation by a rigid cylindrical indenter will be considered. The results will be discussed before concluding remarks.

\section{Algorithm for viscoelastic contacts}

The stress-strain relations for an incompressible elastic solid may be written as either:

$$
s_{i j}=2 \mu_{e} e_{i j}
$$

and

$$
e_{i j}=\frac{1}{2 \mu_{e}} s_{i j}
$$


where $\mu_{e}$ is the elastic shear modulus, $s_{i j}$ is the deviatoric components of stress and $e_{i j}$ is the deviatoric components of strain. The corresponding relationships for a linear viscoelastic material can be expressed by the creep and relaxation functions (Volterra equation):

$$
s_{i j}(t)=\int_{0}^{t} G(t-\tau) \frac{d e_{i j}(\tau)}{d \tau} d \tau
$$

where $G(t)$ is the relaxation function, which specifies the stress response to a unit step change of strain,

$$
e_{i j}(t)=\int_{0}^{t} J(t-\tau) \frac{d s_{i j}(\tau)}{d \tau} d \tau
$$

where $J(t)$ is the creep function, which specifies the strain response to a unit step change of stress. This approach can be applied if the contact area is increasing.

We consider a rigid indenter of arbitrary shape $z(x, y)$ being pressed into contact with a viscoelastic solid. Under the action of a normal force the penetration of the indenter $\delta(t)$ and the contact area will both grow with time and the distribution of contact pressure $p(x, y, t)$ will change. We wish to find the relations which link the pressure distribution, the resultant force $F(t)$ on the indenter and the penetration on the assumption that the surfaces are frictionless. Using Cartesian coordinates, the surface of the viscoelastic half-space before loading corresponds to the $(x, y)$ plane, as illustrated in Fig. 1. The boundary conditions $(z=0)$ of our problem are given by

$$
\left\{\begin{array}{l}
u_{z}(x, y, t)=\delta(t)-h(t)|z(x, y)|, \quad(x, y) \in \Omega(t), \\
\sigma_{y z}=\sigma_{z z}=\sigma_{z x}=0, \quad(x, y) \notin \Omega(t) .
\end{array}\right.
$$


where $u_{z}(x, y, t)$ is the normal component of the displacement of the point on the surface of the half-space, $h(t)$ is the Heaviside step function, $\sigma_{i j}$ is the stress tensor, $\Omega(t)$ is the current contact area.

The Boussinesq problem [1], involving the normal displacement of the point $(x, y)$ on the surface of the half-space, due to the normal concentrated force $p$, for the elastic case may be written as:

$$
u_{z}(x, y)=\frac{(1-\nu)}{\pi} \frac{1}{2 \mu_{e}} \frac{p}{\rho}, \quad \rho=\sqrt{(x-\xi)^{2}+(y-\eta)^{2}}
$$

where Poisson's ratio $\nu$ has been taken as a constant.

Definition 1: The Laplace transform $\bar{f}(s)$ of function $f(t)$ ( $f$ is a continuous function on $t \in[0, \infty)$ and has exponential order as $t \rightarrow \infty)$ :

$$
\bar{f}(s)=\mathcal{L}\{f(t)\}=\int_{0}^{\infty} f(t) e^{-s t} d t
$$

Definition 2: The Stieltjes convolution $\varphi * d \psi$ of two function $\varphi(t)$ and $\psi(t)$ is defined by:

$$
\varphi * d \psi=\int_{-\infty}^{t} \varphi(t-\tau) \frac{d \psi(\tau)}{d \tau} d \tau
$$

where $\psi(t) \rightarrow 0, t \rightarrow-\infty$ and $\varphi(t)$ is continuous for $t \in[0, \infty)$

\section{Theorem 1 (Convolution theorem):}

$$
\mathcal{L}\{\varphi * d \psi\}=s \mathcal{L}\{\varphi\} \mathcal{L}\{\psi\} \quad \text { or } \quad \overline{\varphi * d \psi}=s \bar{\varphi} \bar{\psi}
$$

The Laplace transform of viscoelastic stress-strain relation is given by:

$$
\overline{u_{z}}(x, y, s)=\frac{(1-\nu)}{\pi} s \bar{J}(s) \frac{\bar{p}(s)}{\rho}
$$


Here the creep function $J(t)$ is related with the the relaxation function $G(t)$ by $\bar{J}(s)=\frac{1}{s^{2} \bar{G}}$.

Using the convolution theorem and generalizing the result to include a distribution of forces, we get:

$$
u_{z}(x, y, t)=\frac{(1-\nu)}{\pi} \mathcal{L}^{-1}\left\{s \bar{J}(s) \frac{\bar{p}(s)}{\rho}\right\}=\frac{(1-\nu)}{\pi} J * d\left[\iint_{\Omega_{m}} \frac{p(\xi, \eta, \tau) d \xi d \eta}{\rho}\right]
$$

where $\Omega_{m}$ is the maximum contact area (the contact area can "pulsate" when a load is applied and then removed).

Thus, the analogue problem for the viscoelastic case with the boundary condition may be written as:

$$
\begin{aligned}
u_{z}(x, y, t) & =\frac{(1-\nu)}{\pi} \int_{0}^{t} J(t-\tau) \frac{d}{d \tau}\left[\iint_{\Omega_{m}} \frac{p(\xi, \eta, \tau) d \xi d \eta}{\rho}\right] d \tau= \\
& =\frac{(1-\nu)}{\pi} \int_{0}^{t} J(t-\tau)\left[\iint_{\Omega_{m}} \frac{1}{\rho} \frac{d p(\xi, \eta, \tau)}{d \tau} d \xi d \eta\right] d \tau \\
& =\delta(t)-h(t)|z(x, y)|, \quad(x, y) \in \Omega(t)
\end{aligned}
$$

A surface of the half-space of size $L_{x} \times L_{y}$ was meshed using $N=n_{x} n_{y}$ rectangular elements of dimensions $d x=\frac{L_{x}}{n_{x}}$ and $d y=\frac{L_{y}}{n_{y}}$ with centres in $\left(x_{i}, y_{i}\right)$ and with uniform pressures acting on each of them (Fig. 2). The time 
discretization is $\tau=n_{\tau} d \tau$. We will represent the equation (9) in the form

$$
\sum_{k=1}^{l} J((l-k) d \tau) \sum_{j=1}^{n} T_{i j} \frac{p_{j}^{k}-p_{j}^{k-1}}{d \tau} d \tau=\delta^{l}-z_{i}, \quad i=1 \ldots n
$$

where $p_{j}^{k}=p\left(x_{j}, y_{j}, k d \tau\right), \delta^{l}=\delta(l d \tau), z_{i}=z\left(x_{i}, y_{i}\right)$ and $n=n(t)$ is the number of contact elements for the time $t$. The influence coefficient $T_{i j}$, which expresses the displacement at a general point $i$ due to a unit pressure element centred at point $j$, was calculated using Love's results [20] for a rectangular surface acting on an elastic half-space

$$
T_{i j}=\frac{(1-\nu)}{\pi} \int_{y_{j}-\frac{d y}{2}}^{y_{j}+\frac{d y}{2}} \int_{x_{j}-\frac{d x}{2}}^{x_{j}+\frac{d x}{2}} \frac{d \xi d \eta}{\sqrt{\left(x_{i}-\xi\right)^{2}+\left(y_{i}-\eta\right)^{2}}}
$$

Then equation (10) is written in the form

$$
\begin{aligned}
& J(0) \sum_{j=1}^{n} T_{i j} p_{j}^{l}=\delta^{l}-z_{i}-v_{i}^{l-1}, \quad i=1 \ldots n \\
& v_{i}^{l-1}=\sum_{k=1}^{l-1} J((l-k) d \tau) \sum_{j=1}^{n} T_{i j} \frac{p_{j}^{k}-p_{j}^{k-1}}{d \tau} d \tau-J(0) \sum_{j=1}^{n} T_{i j} p_{j}^{l-1}
\end{aligned}
$$

Here it is necessary to take note of a correct comparison of $p_{j}^{k}$ with $p_{j}^{k-1}$ since the number of contact elements is different for $k$ and $k-1$. For solving this problem one can introduce the matrix $\mathbf{T}$ of dimension $n_{m} \times n_{m}$ and the vector $\bar{p}$ of dimension $n_{m}$ (the maximum number of contact elements, corresponding to $\left.\Omega_{m}\right)$. Now it is possible to determine $p_{j}^{l}$ for a given history of loadings using the MIM which was programmed following the algorithm described in [17]. According to this algorithm, after solving equation (12), some values of $p_{j}^{l}$ 
may be negative and for the next iteration these mesh points are excluded from the assumed contact area and the pressure there is taken to be zero. Here $\delta^{l}$ is imposed, but if we add the equation

$$
\sum_{j=1}^{n} p_{j}^{l} d x d y=F^{l}
$$

it is possible to determine $p_{j}^{l}$ and $\delta^{l}$ for a given history of the resultant normal contact force on the indenter $F^{l}$.

Equations (11), (12) and (13) have been programmed and numerical examples will be presented in the next section and compared with analytical solutions when available.

\section{Numerical examples}

3.1 The indentation of a viscoelastic half-space by a rigid spherical indenter

The MIM was first compared to the analytical results for a single spherical indenter of radius $R$ acting on a viscoelastic half-space. The analytical result of Ting [7] and Graham [21] which was used for comparisons is described in the book of Christensen [22].

$$
\begin{gathered}
\delta(t)=\frac{a^{2}(t)}{R}-\frac{1}{R} \int_{t_{m}}^{t} J(t-\theta) \frac{d}{d \theta}\left[\int_{t_{1}(\theta)}^{\theta} G(\theta-\tau) \frac{d a^{2}(\tau)}{d \tau} d \tau\right] d \theta \\
p(x, y, t)=\frac{2}{\pi(1-\nu) R} \int_{0}^{t_{1}(t)} G(t-\tau) \frac{d \sqrt{a^{2}(\tau)-x^{2}-y^{2}}}{d \tau} d \tau
\end{gathered}
$$


where $a(t)$ is the contact radius. The resultant normal contact force $F(t)$ on the indenter acting on a viscoelastic half-space can be calculated as follows:

$$
F(t)=\int_{0}^{2 \pi} \int_{0}^{a(t)} r p(r, t) d \varphi d r=\frac{4}{3(1-\nu) R} \int_{0}^{t_{1}(t)} G(t-\tau) \frac{d a^{3}(\tau)}{d \tau} d \tau
$$

Here $t_{1}$ is a new time variable (Fig. 3)

$$
\left\{\begin{array}{l}
t_{1}(t)=t, \quad t \leq t_{m} \\
a\left(t_{1}\right)=a(t), \quad t \geq t_{m} \quad\left(t_{1}<t_{m}\right)
\end{array}\right.
$$

$t_{m}$ is the maximum of $a(t)$. So, $t_{1}$ is the time prior to $t_{m}$, whereby the contact radius $a(t)$ (when the contact area is decreasing) is equal to the prior contact radius $a\left(t_{1}\right)$ (when the contact area was increasing). Thus, the contact pressure and the contact force depend only upon the variation of contact area prior to $t_{1}$.

In the following examples the stress history is represented in the form of a Prony's series:

$$
\sigma(t)=\left(E_{\infty}+\left(E_{0}-E_{\infty}\right) e^{-\frac{t}{\tau_{c}}}\right) \varepsilon_{0}
$$

where $\tau_{c}$ is the characteristic time, $E_{0}$ is the instantaneous Young's modulus, $E_{\infty}$ is the statical Young's modulus, $\varepsilon_{0}$ is the instantaneous strain. Then the creep and the relaxation functions may be written as follows:

$$
\left\{\begin{array}{l}
G(t)=E_{\infty}+\left(E_{0}-E_{\infty}\right) e^{-\frac{t}{\tau_{c}}}, \\
J(t)=\frac{1}{E_{\infty}}-\frac{\left(E_{0}-E_{\infty}\right)}{E_{0} E_{\infty}} e^{-\frac{E_{\infty}}{E_{0}} \frac{t}{\tau_{c}}}
\end{array}\right.
$$


Now for the numerical calculations we take the following parameter values $E_{\infty}=7.5 \mathrm{MPa}, E_{0}=15 \mathrm{MPa}, \tau_{c}=1 \mathrm{~s}$ and $R=5 \mathrm{~mm}$. The contact radius $a(t)=2.2 \sin \left(\frac{\pi t}{L_{t}}\right)$ is imposed with the duration of loading $L_{t}=5 \mathrm{~s}$, so that the penetration $\delta(t)$ varies between 0 and $1 \mathrm{~mm}$. A comparison between the contact forces computed by the MIM with $n_{\tau}=201, n_{x}=n_{y}=81$, $L_{t}=5 \mathrm{~s}, L_{x}=L_{y}=20 \mathrm{~mm}$ and the analytical formula is made in Fig. 4. The difference between analytical and numerical solutions is small, showing a very good agreement. One can see the asymmetry between increasing and decreasing loadings of the viscoelastic curve. At the beginning both solutions are close to the elastic solution with Young's modulus $E_{0}$ and at the end are close to the elastic solution with Young's modulus $E_{\infty}$.

Fig. 5 shows an example of a strongly time dependent material behaviour with the parameters $E_{\infty}=0.9 \mathrm{MPa}, E_{0}=9 \mathrm{MPa}, \tau_{c}=0.3 \mathrm{~s}$ and $n_{\tau}=601$, $n_{x}=n_{y}=81, L_{t}=5 \mathrm{~s}, L_{x}=L_{y}=20 \mathrm{~mm}$. The normal contact force on the indenter equals zero at $t=5 \mathrm{~s}$ even if the penetration does not yet equal zero. One can see also the asymmetry of the curve and the rapid change of the slope. For the next examples the parameters $E_{\infty}=7.5 \mathrm{MPa}, E_{0}=15 \mathrm{MPa}, \tau_{c}=1$ $\mathrm{s}$ are chosen and will not be changed. Now the penetration $\delta(t)=\sin \left(\frac{\pi t}{L_{t}}\right)$ is imposed. Again, at the beginning the numerical solution is close to the elastic solution with Young's modulus $E_{0}$ (Fig. 6) and at the end is close to the elastic solution with Young's modulus $E_{\infty}$. The reason of intersection of viscoelastic and elastic solutions is the memory of the viscoelastic material and for the same reason, the contact force vanishes already while the penetration does not yet equal zero.

The distribution of the pressure $p(0, y, t)$ for $t=2.5 \mathrm{~s}$ is represented in Fig. 7 with $n_{\tau}=401, n_{x}=n_{y}=101, L_{t}=5 \mathrm{~s}, L_{x}=L_{y}=10 \mathrm{~mm}$. The differ- 
ence between the viscoelastic analytical and viscoelastic numerical solutions $p(0, y, t)$ is small showing a good agreement.

In Fig. 8 the dependence of the force versus the penetration $\delta(t)=V t$ for different values of loading velocity $V=1,10,1000 \mathrm{~mm} / \mathrm{s}$ and $n_{\tau}=401, n_{x}=$ $n_{y}=81, L_{t}=1 \mathrm{~s}, L_{x}=L_{y}=20 \mathrm{~mm}$ is illustrated. The difference between the graphics which correspond to $V=10 \mathrm{~mm} / \mathrm{s}$ and $V=1000 \mathrm{~mm} / \mathrm{s}$ is small while the difference between the graphics which correspond to $V=1$ $\mathrm{mm} / \mathrm{s}$ and $V=10 \mathrm{~mm} / \mathrm{s}$ is much larger. The reason is the characteristic time of material $\tau_{c}$ which equals $1 \mathrm{~s}$. Hence for $V=1 \mathrm{~mm} / \mathrm{s}$ the loading time $t=\frac{\delta}{V}=1 \mathrm{~s}=\tau_{c}$. On the contrary for $V=10 \mathrm{~mm} / \mathrm{s}$ and $V=1000 \mathrm{~mm} / \mathrm{s}$ the loading time and the characteristic time of the material are very different.

In addition, the iterative method converges, as shown in Fig. 9

\subsection{The indentation of a viscoelastic half-space by a rigid conical indenter}

The MIM was secondly compared to the analytical result for a single conical indenter of semi-opening angle $\theta$ acting on a viscoelastic half-space when a contact radius increases monotonically. The elastic solution of Love [23] (and later Vilke [24]) may be written:

$$
F=\frac{4}{\pi} \operatorname{tg} \theta 2 \mu_{e} \delta^{2}
$$

Following Radok's suggestion, we rewrite equation (20), replacing the elastic constant in the elastic solution by the corresponding integral operator:

$$
F(t)=\frac{4}{\pi} \operatorname{tg} \theta \int_{0}^{t} G(t-\tau) \frac{d \delta^{2}(\tau)}{d \tau} d \tau
$$


A comparison between the contact forces computed by the MIM with $n_{\tau}=$ 401, $n_{x}=n_{y}=201, L_{t}=5 \mathrm{~s}, L_{x}=L_{y}=20 \mathrm{~mm}, \theta=45^{\circ}$ and the analytical formula (21) is shown in Fig. 10. This difference between the contact forces is small, showing a very good agreement. Here the penetration $\delta(t)=\sin \left(\frac{\pi t}{L_{t}}\right)$ is imposed and we have the same effect as previously for the spherical case: at the beginning the numerical solution is close to the elastic solution with Young's modulus $E_{0}$ and at the end is close to the elastic solution with Young's modulus $E_{\infty}$.

The distribution of the pressure $p(0, y, t)$ for $t=2.5 \mathrm{~s}$ is represented in Fig. 11 with $n_{\tau}=401, n_{x}=n_{y}=181, L_{t}=5 \mathrm{~s}, L_{x}=L_{y}=7 \mathrm{~mm}$. The maximum pressure is concentrated in the centre of contact area. The absolute value of pressure is much higher than for the spherical case but the contact area is much less. The elastic solutions $p(0, y, t)$ with Young's modulus $E_{0}$ and $E_{\infty}$ are also plotted as a reference.

\subsection{The indentation of a viscoelastic half-space by a rigid cylindrical indenter}

Now a cylindrical indenter of radius $R=5 \mathrm{~mm}$ and of width $l=3 \mathrm{~mm}$ is considered. The penetration $\delta(t)=\sin \left(\frac{\pi t}{L_{t}}\right)$ is imposed. The distribution of the pressure for $t=2.5 \mathrm{~s}$ is represented in Fig. 12 with $n_{\tau}=401, n_{x}=n_{y}=101$, $L_{t}=5 \mathrm{~s}, L_{x}=L_{y}=10 \mathrm{~mm}$. The maximum pressure is concentrated at the boundaries of the contact area (the axis $y$ is the axis of symmetry of the cylinder). The absolute value of pressure is much higher than for the spherical case but less than for the conical case. In Fig. 13 the difference between the viscoelastic solution for $t=t_{1}=1.25 \mathrm{~s}$ (increasing load) and viscoelastic solution for $t=t_{2}=3.05 \mathrm{~s}$ (decreasing load) is displayed. The 
pressure distributions $p\left(x, 0, t_{1}\right)$ and $p\left(x, 0, t_{2}\right)$ are represented in Fig. $13(a)$ and the pressure distributions $p\left(0, y, t_{1}\right)$ and $p\left(0, y, t_{2}\right)$ are represented in Fig. $13(b)$. It is very interesting to notice that the resultant normal contact forces on the indenter almost equal $F\left(t_{1}\right) \approx F\left(t_{2}\right)$ (Fig. 14), while the distribution of the pressure for $t=t_{1}$ and $t=t_{2}$ are different i.e. $p\left(x, y, t_{1}\right) \neq p\left(x, y, t_{2}\right)$.

In Fig. 15 the dependence of force versus the penetration for two different values of velocity of loading $V=1 \mathrm{~mm} / \mathrm{s}, V=10 \mathrm{~mm} / \mathrm{s}$ and $n_{\tau}=401$, $n_{x}=n_{y}=81, L_{t}=\frac{2}{V} \mathrm{~s}, L_{x}=L_{y}=20 \mathrm{~mm}$ is illustrated. The penetration is imposed as follows:

$$
\delta(t)=\left\{\begin{array}{l}
V t, \quad t<\frac{1}{V} \\
-V t+2, \quad t>\frac{1}{V}
\end{array}\right.
$$

In this case the penetration $\delta(t)$ increases monotonically to $1 \mathrm{~mm}$ and then decreases monotonically to $0 \mathrm{~mm}$. As previously, for the spherical case, the difference between the two curves is large. The reason is the same : the characteristic time of the material $\tau_{c}$ equals $1 \mathrm{~s}$. Also here hysteresis is observed in the force-penetration curve as viscoelastic substance loses energy when a load is increasing, then decreasing.

\section{Conclusions}

The Matrix Inversion Method (MIM) introduced by Kalker and used for the analysis of elastic contact, has been extended to the equivalent viscoelastic problem so that the problem can be solved for different loading histories and for indenters of arbitrary shape. The numerical results were first compared to 
the analytical results for a single spherical indenter acting on a viscoelastic half-space. Then the comparison was made in case of a single conical indenter when the contact radius increases monotonically. The contact force and the pressure distribution computed by the MIM agree well with the analytical solutions. The contact force as a function of time, the pressure distribution, the contact area are found for a single spherical, conical and cylindrical indenter. In all cases the viscoelastic solutions have been compared to the elastic solutions. One can see that viscoelastic curves of contact force versus penetration are different for increasing and decreasing load. Also the influence of the loading velocity on the results has been studied. It is very interesting to notice that when the increasing and decreasing loads almost equal, the corresponding distributions of the pressure are different. The new algorithm allows estimating the influence of the viscoelasticity of materials on the contact. It can for instance be used for tyre-road contact computations. 


\section{Acknowledgements}

This work is supported by ADEME in the frame of the French and German Cooperation P2RN project.

\section{References}

[1] Boussinesq J. Application des potentiels à l'étude de l'équilibre et du mouvement des solides élastiques. Gauthier-Villars, Paris, 1885.

[2] Hertz H. Über die Berührung fester elastischer Körper (On the contact of elastic solids). J. Reine und Angewandte Mathematik 1882;92:156-171.

[3] Hertz H. Über die Berührung fester elastischer Körper and über die Harte (On the contact of rigid elastic solids and on hardness). Verhandlungen des Vereins zur Beförderung des Gewerbefleisses, Leipzig 1882.

[4] Sneddon IN. The relation between load and penetration in the axisymmetric Boussinesq problem for a punch of arbitrary profile. International Journal of Engineering Science 1965;3:47-57.

[5] Gauthier A, Knight PA, McKee S. The Hertz contact problem, coupled Volterra integral equations and a linear complementarity problem. Journal of Computational and Applied Mathematics 2007;206:322-340.

[6] Radok JRM. Viscoelastic stress analysis. Q. App. Math. 1957;15:198.

[7] Ting TCT. The contact stresses between a rigid indenter and a viscoelastic halfspace. Trans. ASME, Series E, Journal of Applied Mechanics 1966;33:845.

[8] Vandamme M, Ulm F-J. Viscoelastic solutions for conical indentation. International Journal of Solids and Structures 2006;43:3142-3165. 
[9] Larsson P-L \& Carlsson S. On microindentation of viscoelastic polymers. Polymer Testing 1998;17:49-75.

[10] Yang WH. The contact problem for viscoelastic bodies. Trans. ASME, Series E, Journal of Applied Mechanics 1966;33:395.

[11] Giannakopoulos AE. Elastic and viscoelastic indentation of flat surfaces by pyramid indentors. Journal of the Mechanics and Physics of Solids 2006;54:13051332.

[12] Murakami Y, Tanaka K, Itokazu M, Shimamoto A. Elastic analysis of triangular pyramid indentation by the finite element method and its application to nanoindentation measurement of glasses. Philos. Mag. 1994;A69:1131-1153.

[13] Larsson P-L, Giannakopoulos AE, Soderlund E, Rowcliffe DJ, Vestergaard R. Analysis of Berkovich indentation. Int. J. Solids Struct. 1996;33:221-248.

[14] Rabinovich VL, Savin VK. Three dimensional modelling of indentation fracture in brittle materials. Mat. Sci. Eng. 1996;A206:208-214.

[15] Cheng L, Xia X, Scriven LE, Gerberich WW. Spherical-tip indentation of viscoelastic material. Mechanics of Materials 2005;37:213-226.

[16] Kalker JJ. Two algorithms for the contact problem in elastostatics. Report of the Department of Mathematics and Informatics, 82-26. Delft University of Technology, 1982.

[17] Johnson KL. Contact Mechanics. Cambridge University Press, 1985.

[18] Yin HP, Cesbron J, Feng ZQ, Duhamel D, Anfosso-Lédée F, Le Houédec D. A two-scale iterative method for solving the problem of multipunch on an elastic halfspace, Part 1: Numerical comparisons. submitted to Int. Journal of Mechanical Sciences. 
[19] Cesbron J, Anfosso-Lédée F, Yin HP, Duhamel D, Le Houédec D, Feng ZQ. A two-scale iterative method for solving the problem of multipunch on an elastic halfspace, Part 2: Experimental comparisons. submitted to Int. Journal of Mechanical Sciences.

[20] Love AEH. Stress produced in a semi-infinite solid by pressure on part of the boundary. In: Phil. Trans. Royal Society 1929;A228:37-43.

[21] Graham GAC. The contact problem in the linear theory of viscoelasticity. International Journal of Engineering Science 1965;3:27-46.

[22] Christensen RM. Theory of Viscoelasticity. An Introduction, second ed., Academic Press, New York 1982.

[23] Love AEH. Boussinesq's problem for a rigid cone. Quarterly Journal of Mathematics (Oxford series) 1939;10:161.

[24] Vilke VG. On Non-Hertzian Contact of Wheel and Rail. Research on Problems of Stability and Stabilization of Motion, Reports of the Computing Centre of the Russian Ac. of Sc.(in press). 


\section{List of Figures}

1 The contact between a rigid indenter of arbitrary shape and a viscoelastic half-space

2 The discretization of the contact problem by rectangular elements

3 A new time variable $t_{1}$

4 Spherical case. The contact radius $a(t)$ is imposed $(a)$ The difference between the contact forces, — viscoelastic analytical, ------ viscoelastic numerical, $. \cdots . .$. elastic with $E_{\infty}=7.5 \mathrm{MPa}, \ldots \ldots \ldots \ldots . .$. elastic with $E_{0}=15 \mathrm{MPa}(b)$ The penetration $\delta(t)$

5 Spherical case. The contact radius $a(t)$ is imposed. Strongly time dependent material (a) The difference between the contact forces, — viscoelastic analytical, ------ viscoelastic numerical (b) The penetration $\delta(t)$

6 Spherical case. The penetration $\delta(t)$ is imposed $(a)$ The difference between the contact forces, — viscoelastic numerical, ------ elastic with $E_{\infty}=7.5 \mathrm{MPa}, \quad \cdots \cdots$ elastic with $E_{0}=15 \mathrm{MPa}(b)$ The penetration $\delta(t)$

$7 \quad$ Spherical case. The pressure distribution for $t=2.5 \mathrm{~s}$ and $x=0 \mathrm{~mm}, \quad$ viscoelastic analytical, ------ viscoelastic numerical 
8 Spherical case. The dependence of force versus the penetration $\delta(t)$ for different values of loading velocity, $-V=1 \mathrm{~mm} / \mathrm{s}$, ----- $V=10 \mathrm{~mm} / \mathrm{s}, \cdots \cdots \cdot V=1000 \mathrm{~mm} / \mathrm{s}$

9 Spherical case. Convergence of the algorithm

10 Conical case. The penetration $\delta(t)$ is imposed. The difference between the contact forces, — viscoelastic analytical, -----viscoelastic numerical, ...... elastic with $E_{\infty}=7.5 \mathrm{MPa}, \ldots \ldots \ldots \ldots$ elastic with $E_{0}=15 \mathrm{MPa}$

11 Conical case. The pressure distribution for $t=2.5 \mathrm{~s}$ and $x=0$ $\mathrm{mm}, \longrightarrow$ viscoelastic numerical, ------ elastic with $E_{\infty}=7.5$ $\mathrm{MPa}, \cdots \cdot$. elastic with $E_{0}=15 \mathrm{MPa}$

12 Cylindrical case. The pressure distribution for $t=2.5 \mathrm{~s}$

13 Cylindrical case. The pressure distribution for $t_{1}=1.25 \mathrm{~s}$ and $t_{2}=3.05 \mathrm{~s}(a) y=0 \mathrm{~mm}, \longrightarrow$ viscoelastic for $t_{1},------$ viscoelastic for $t_{2}(b) x=0 \mathrm{~mm},-$ viscoelastic for $t_{1}$, -----viscoelastic for $t_{2}$

14 Cylindrical case. The penetration $\delta(t)$ is imposed. The difference between the contact forces, — viscoelastic numerical, ------ elastic with $E_{\infty}=7.5 \mathrm{MPa}, \quad$...... elastic with $E_{0}=15 \mathrm{MPa}$

15 Cylindrical case. The dependence of force versus the penetration $\delta(t)$ for different values of loading velocity, $V=1 \mathrm{~mm} / \mathrm{s},------V=10 \mathrm{~mm} / \mathrm{s}$ 


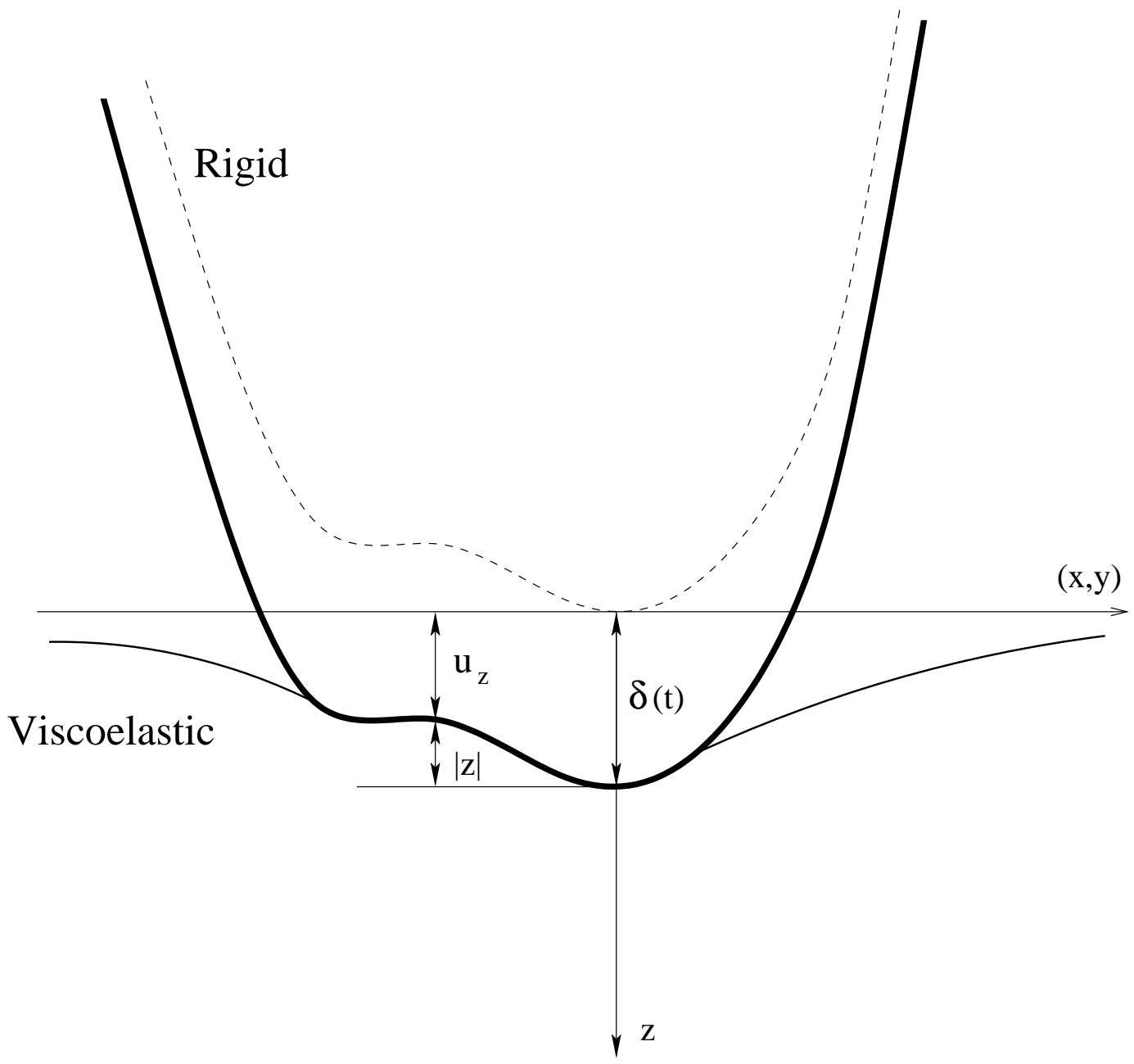

Fig. 1. The contact between a rigid indenter of arbitrary shape and a viscoelastic half-space 


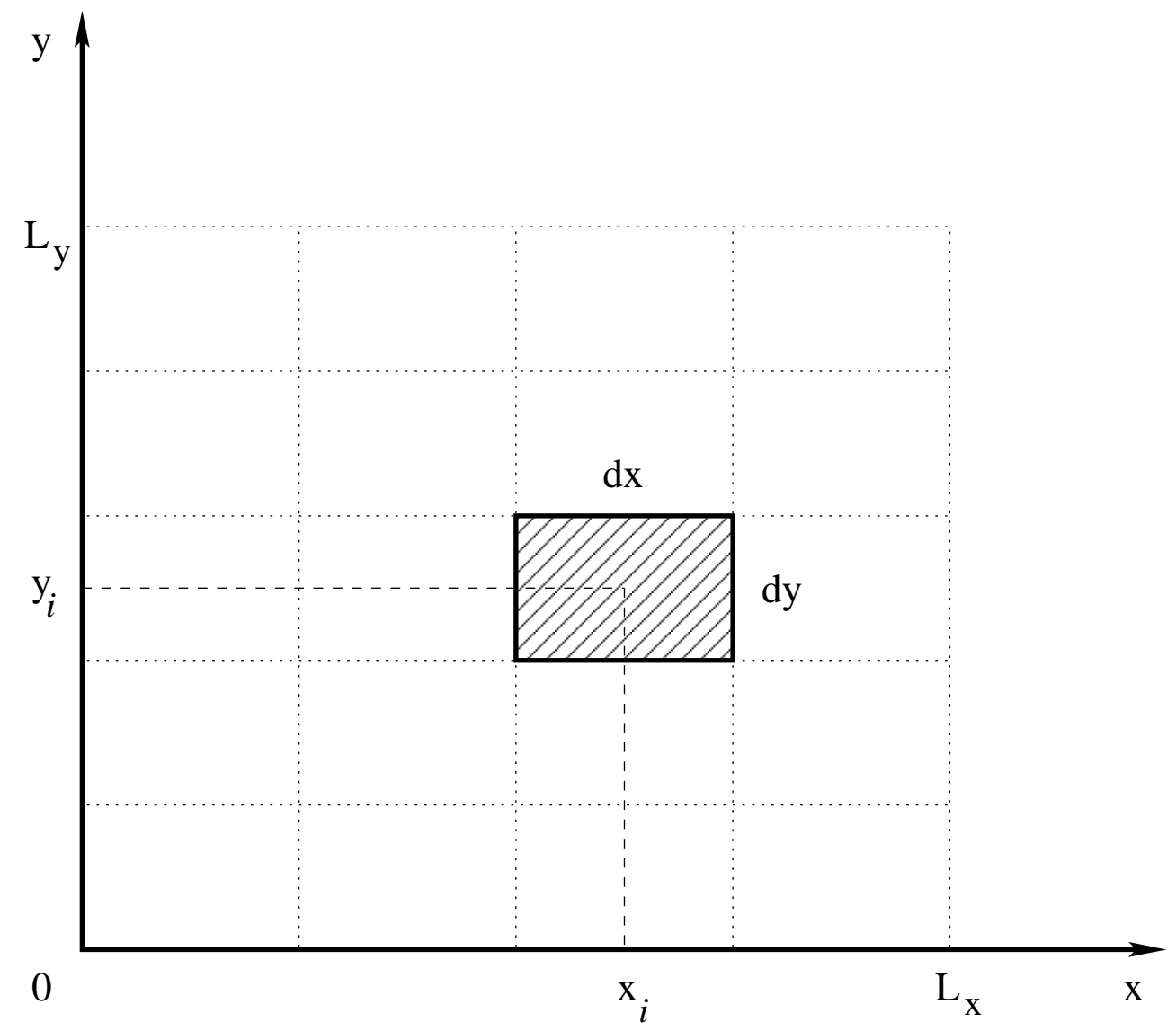

Fig. 2. The discretization of the contact problem by rectangular elements 


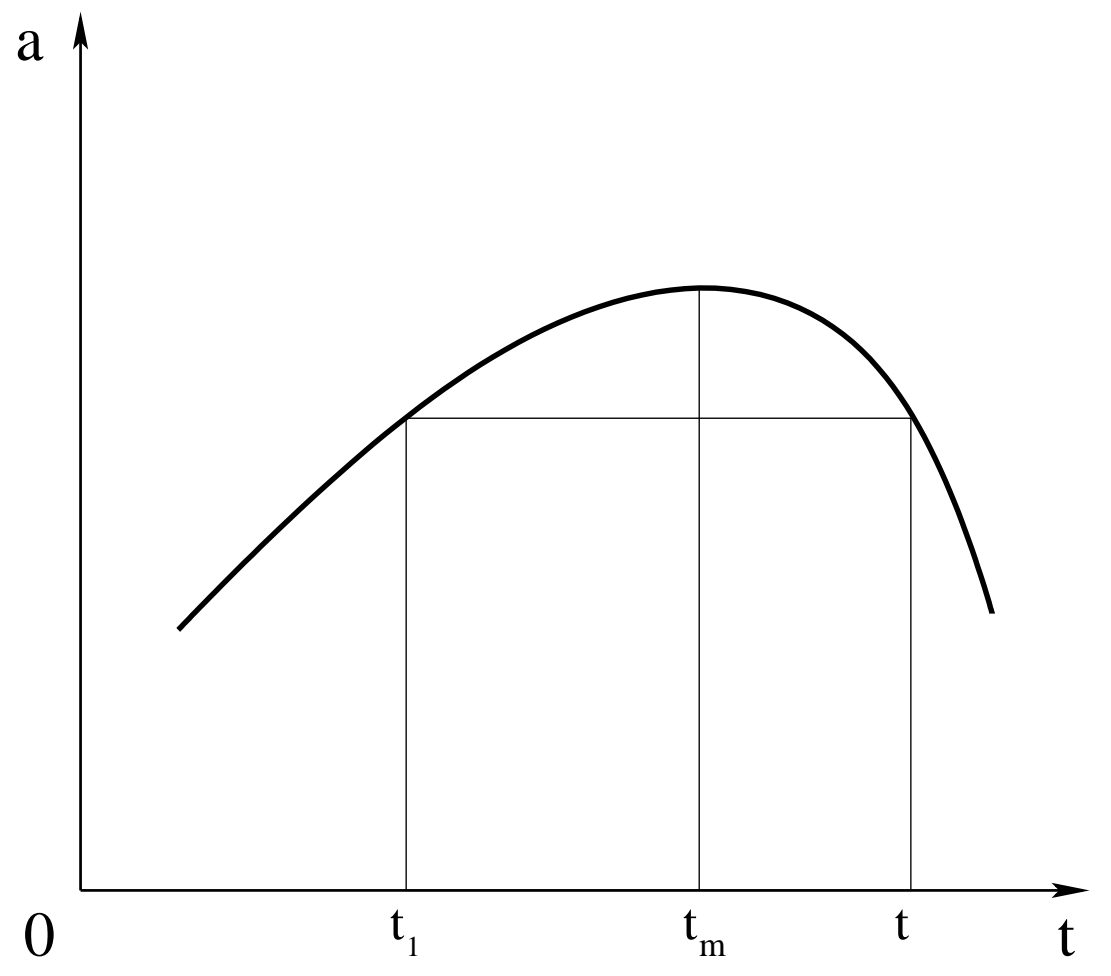

Fig. 3. A new time variable $t_{1}$ 
(a) Viscoelastic spherical case

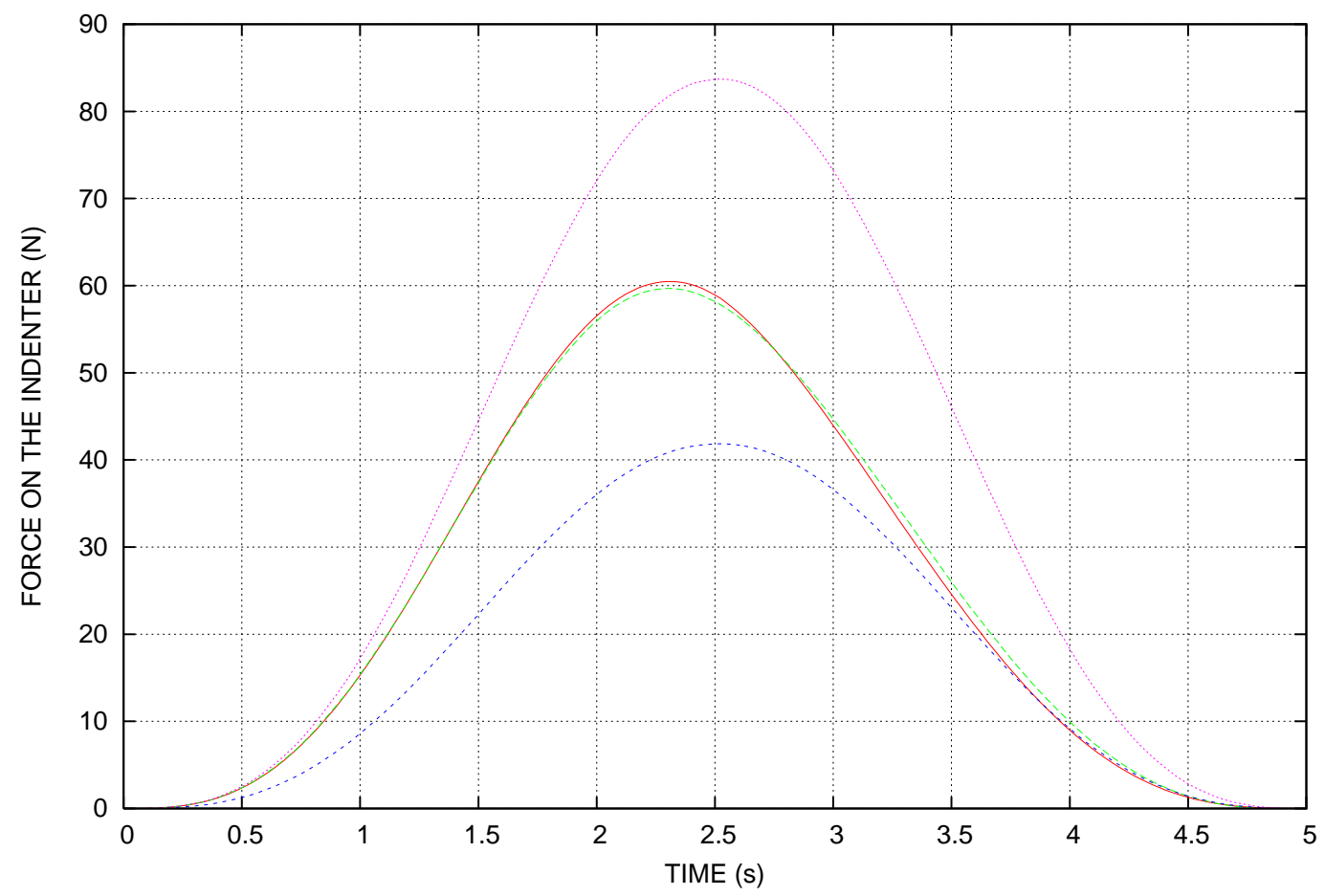

(b) Viscoelastic spherical case

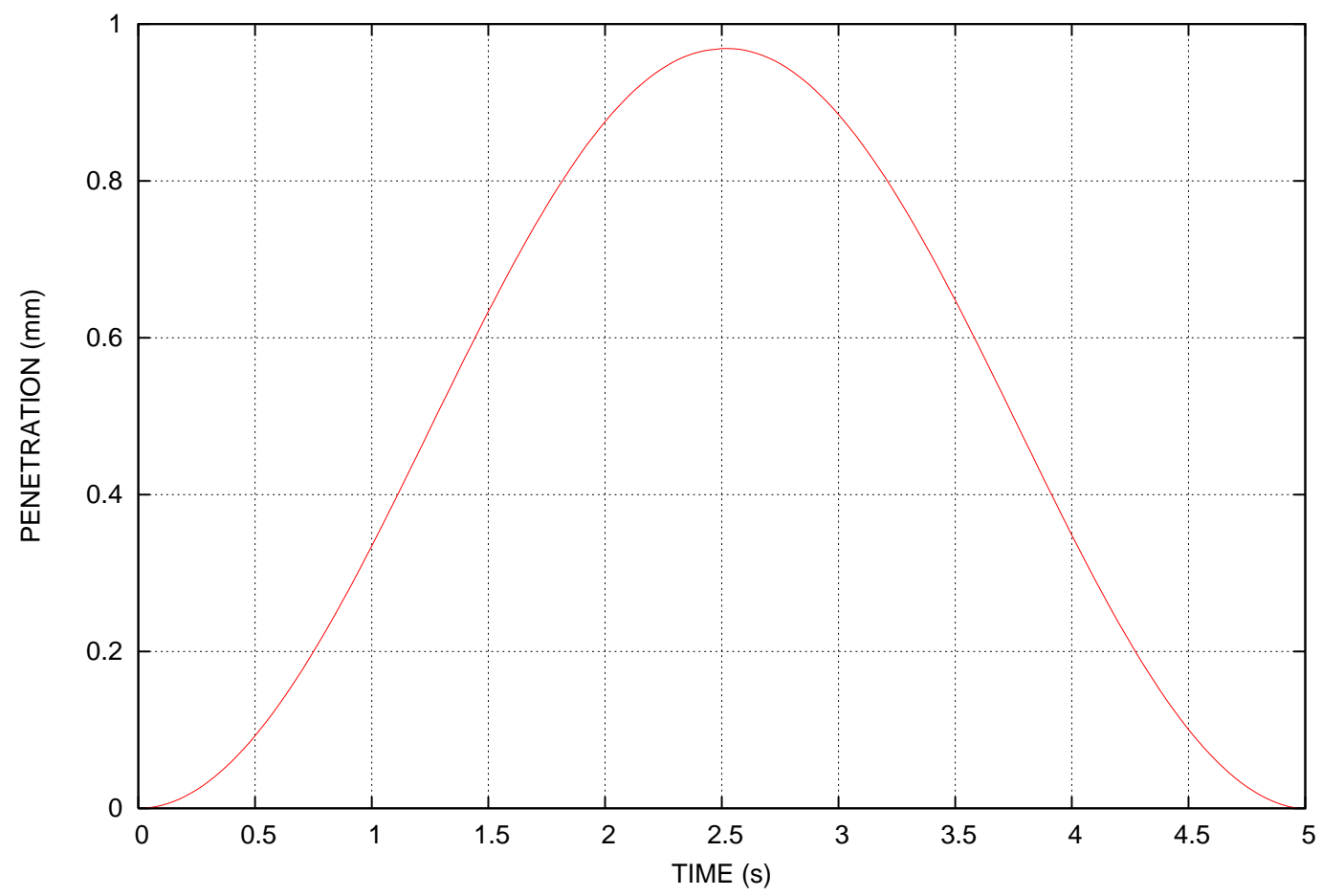

Fig. 4. Spherical case. The contact radius $a(t)$ is imposed $(a)$ The difference between the contact forces, $\_$viscoelastic analytical, ------ viscoelastic numerical, ....... elastic with $E_{\infty}=7.5 \mathrm{MPa}$, ........... elastic with $E_{0}=15 \mathrm{MPa}(b)$ The penetration $\delta(t)$ 
(a) Viscoelastic spherical case

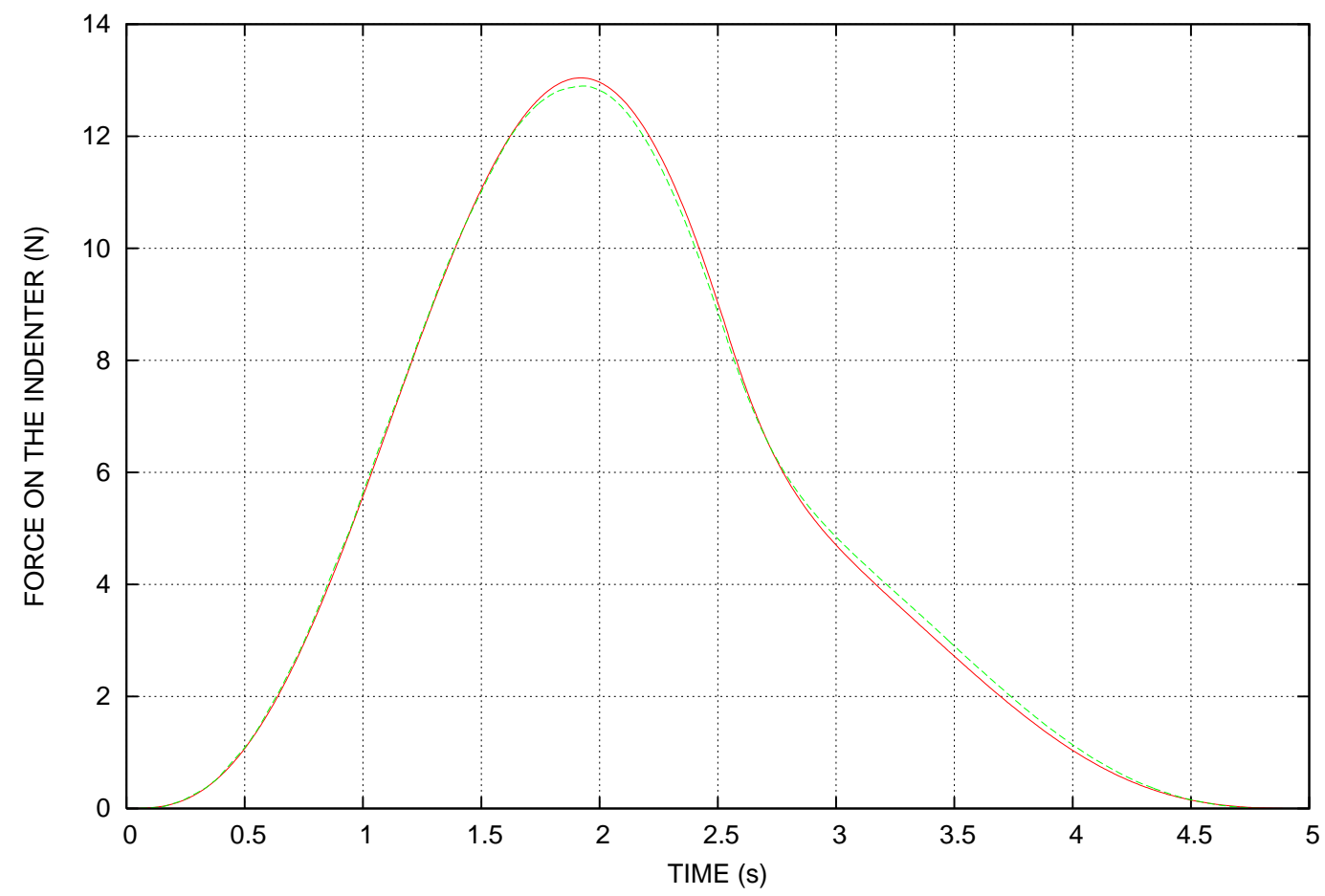

(b) Viscoelastic spherical case

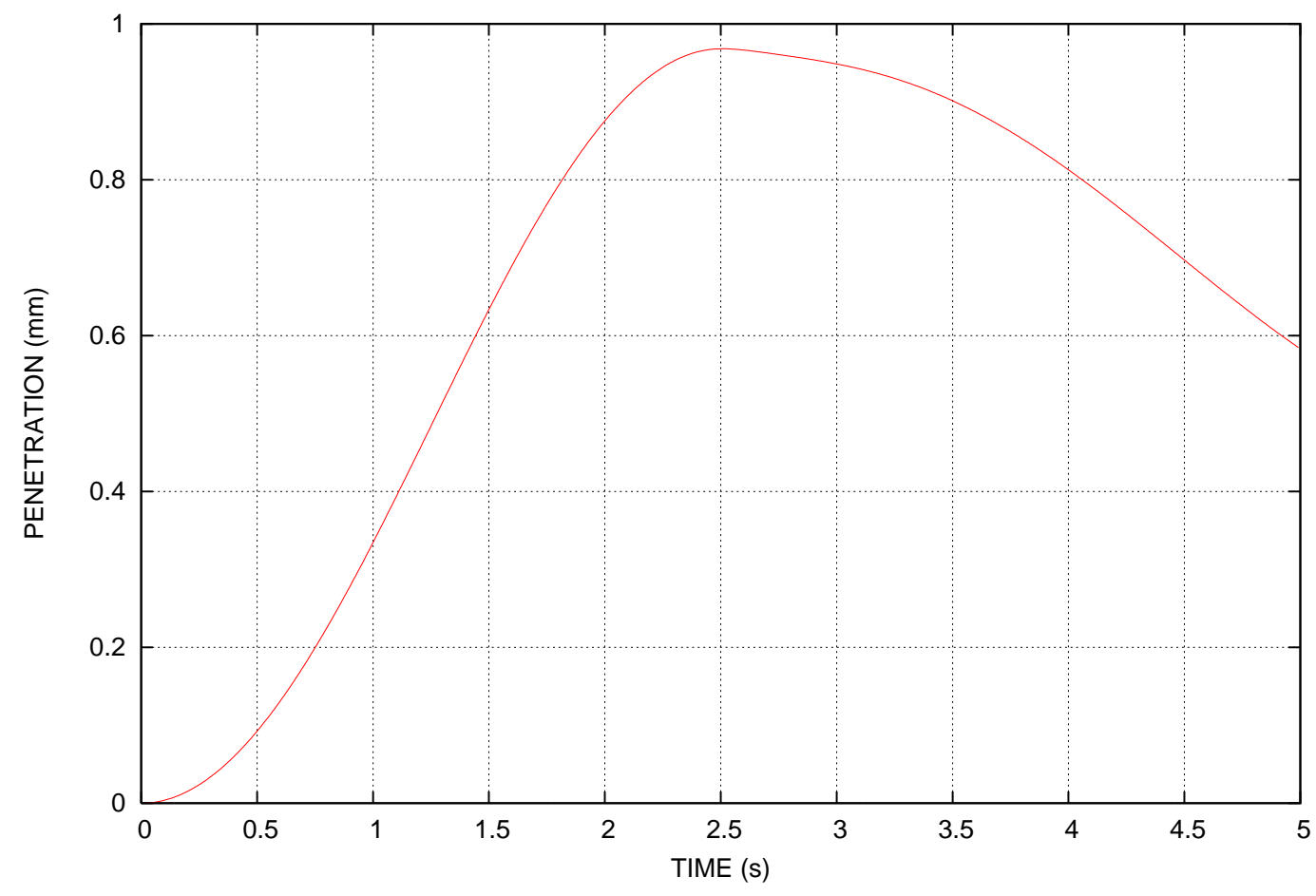

Fig. 5. Spherical case. The contact radius $a(t)$ is imposed. Strongly time dependent material (a) The difference between the contact forces, _ viscoelastic analytical, ------ viscoelastic numerical $(b)$ The penetration $\delta(t)$ 
(a) Viscoelastic spherical case

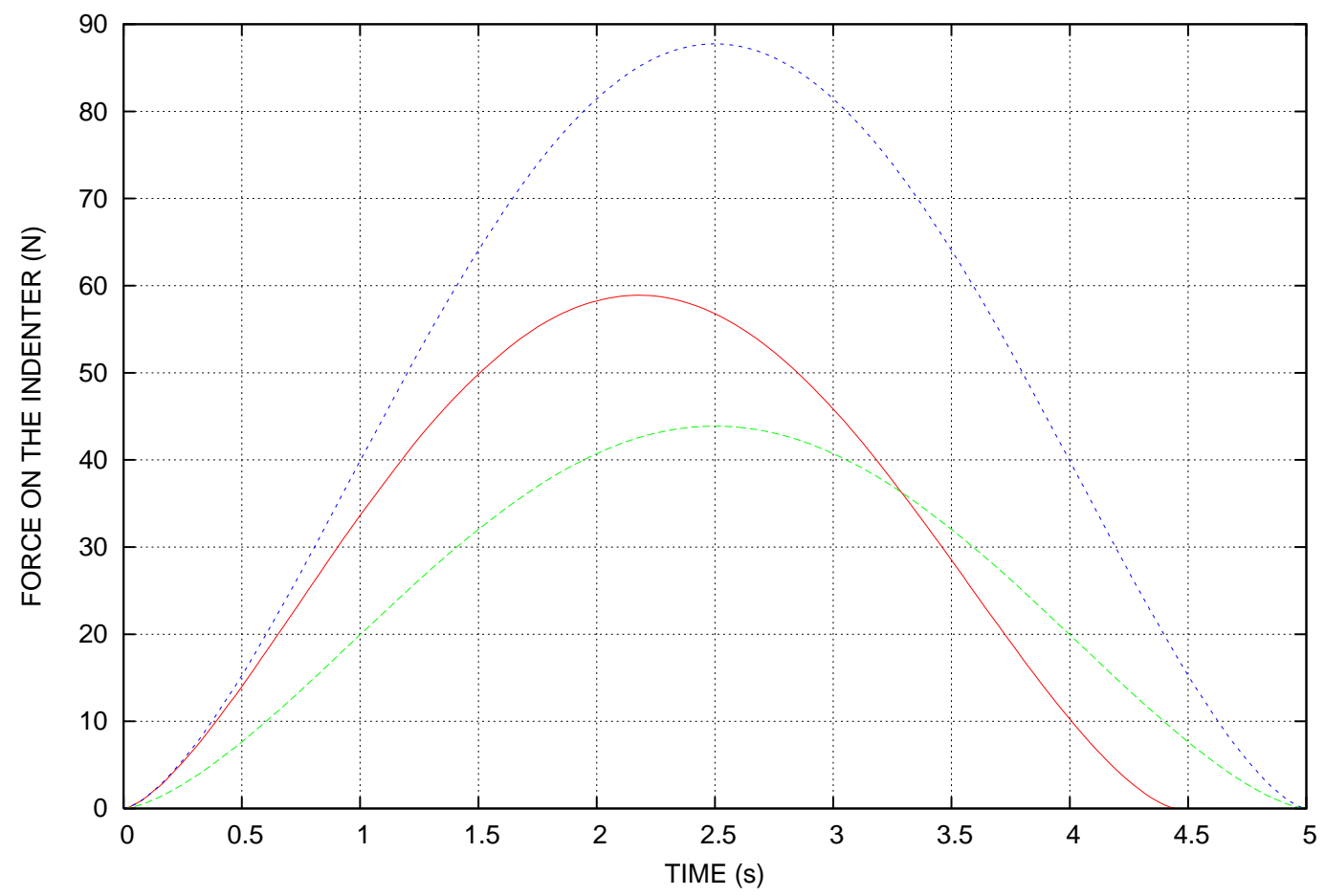

(b) Viscoelastic spherical case

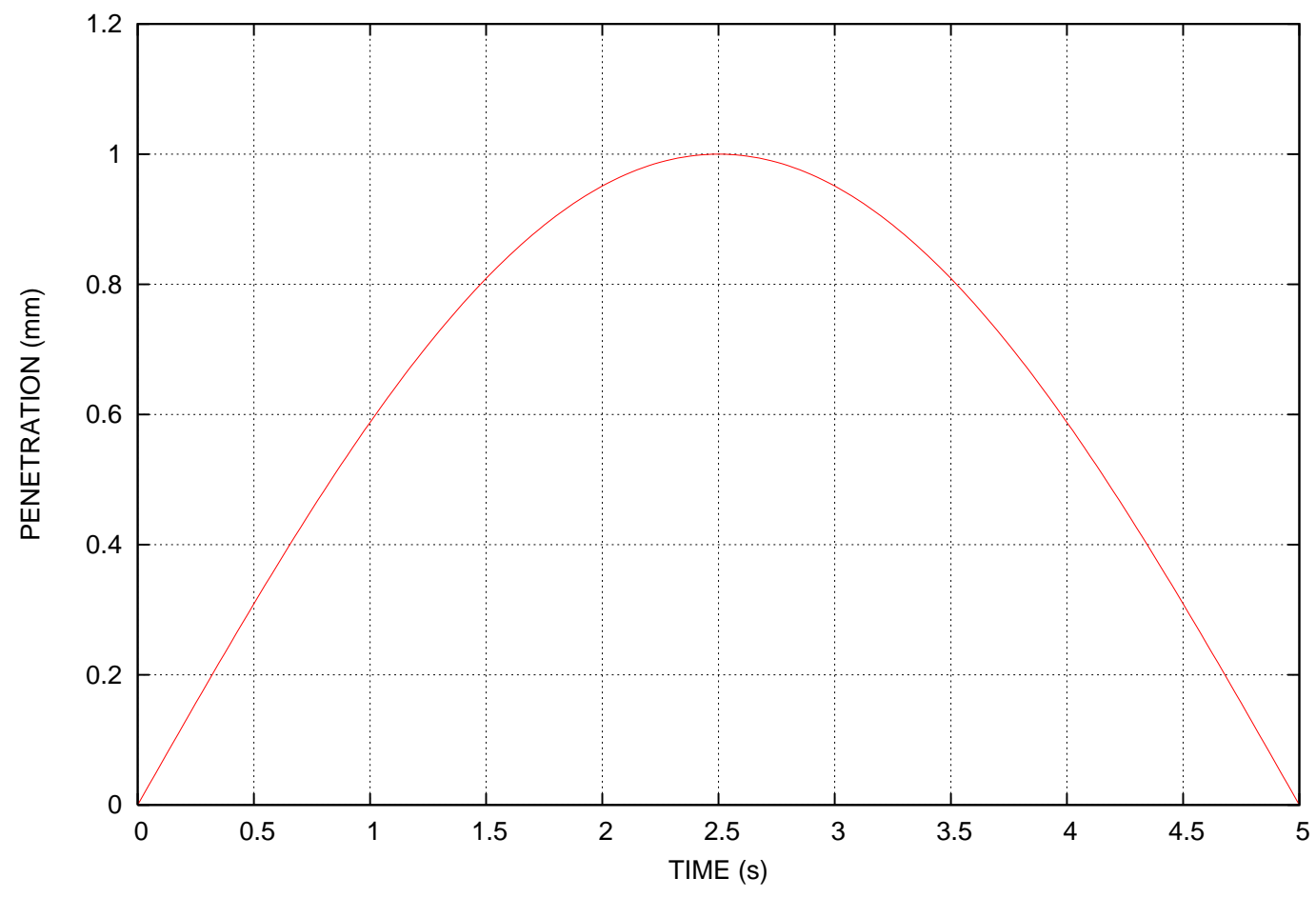

Fig. 6. Spherical case. The penetration $\delta(t)$ is imposed $(a)$ The difference between the contact forces, - viscoelastic numerical, ------ elastic with $E_{\infty}=7.5 \mathrm{MPa}$, …. elastic with $E_{0}=15 \mathrm{MPa}(b)$ The penetration $\delta(t)$ 


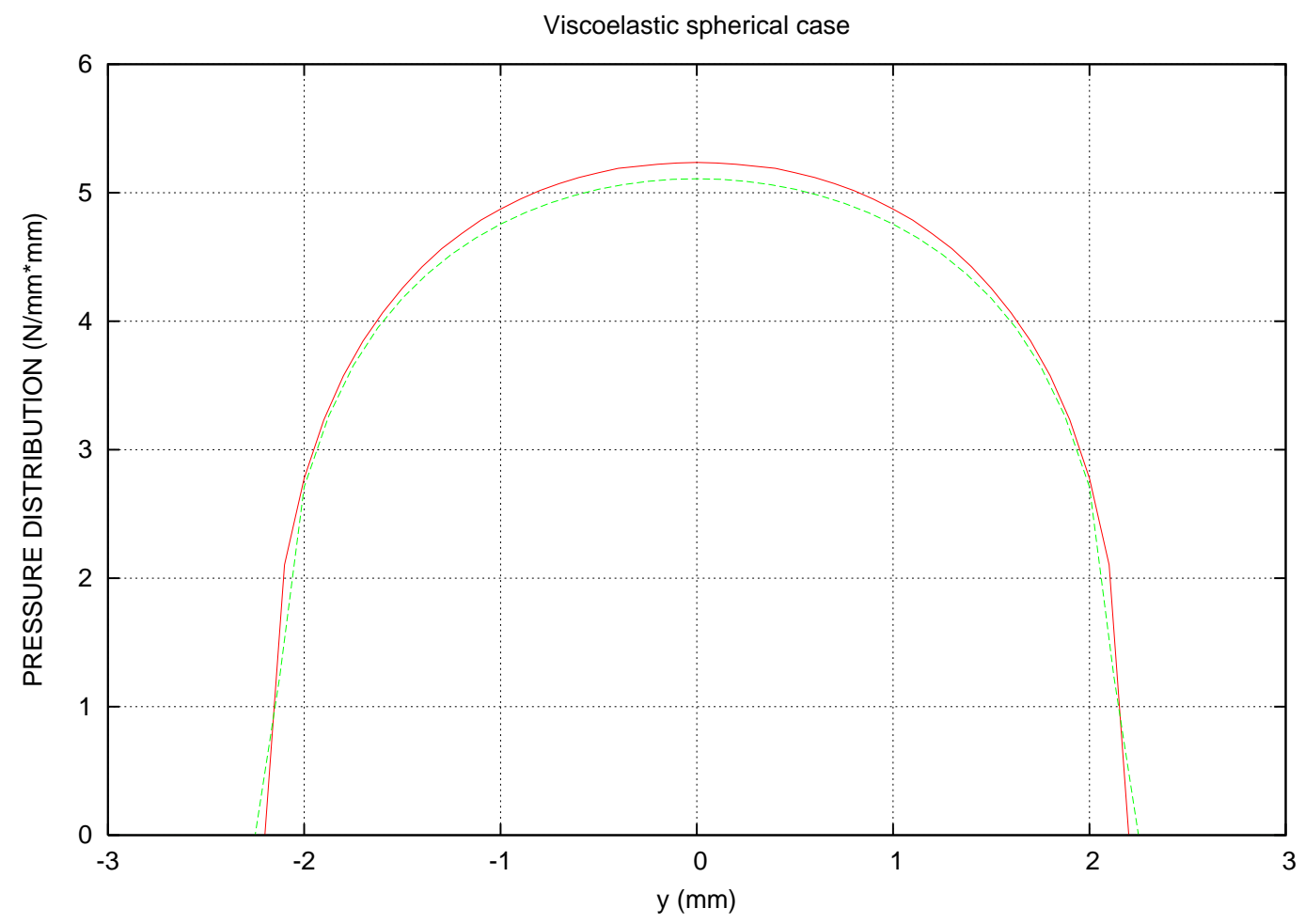

Fig. 7. Spherical case. The pressure distribution for $t=2.5 \mathrm{~s}$ and $x=0 \mathrm{~mm}$, viscoelastic analytical, viscoelastic numerical 


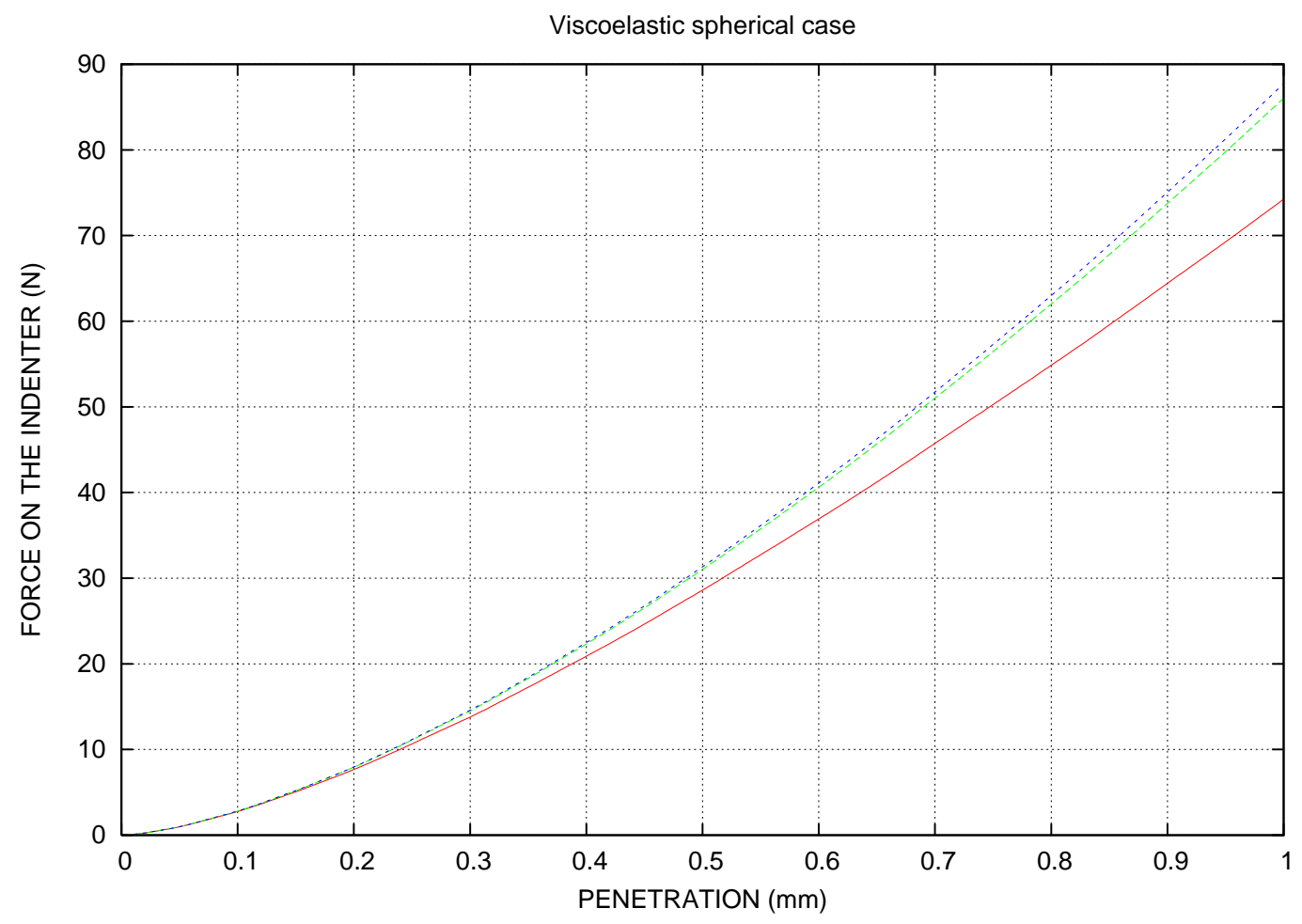

Fig. 8. Spherical case. The dependence of force versus the penetration $\delta(t)$ for different values of loading velocity, $-V=1 \mathrm{~mm} / \mathrm{s},-----V=10 \mathrm{~mm} / \mathrm{s}, \cdots \cdots$ $V=1000 \mathrm{~mm} / \mathrm{s}$ 


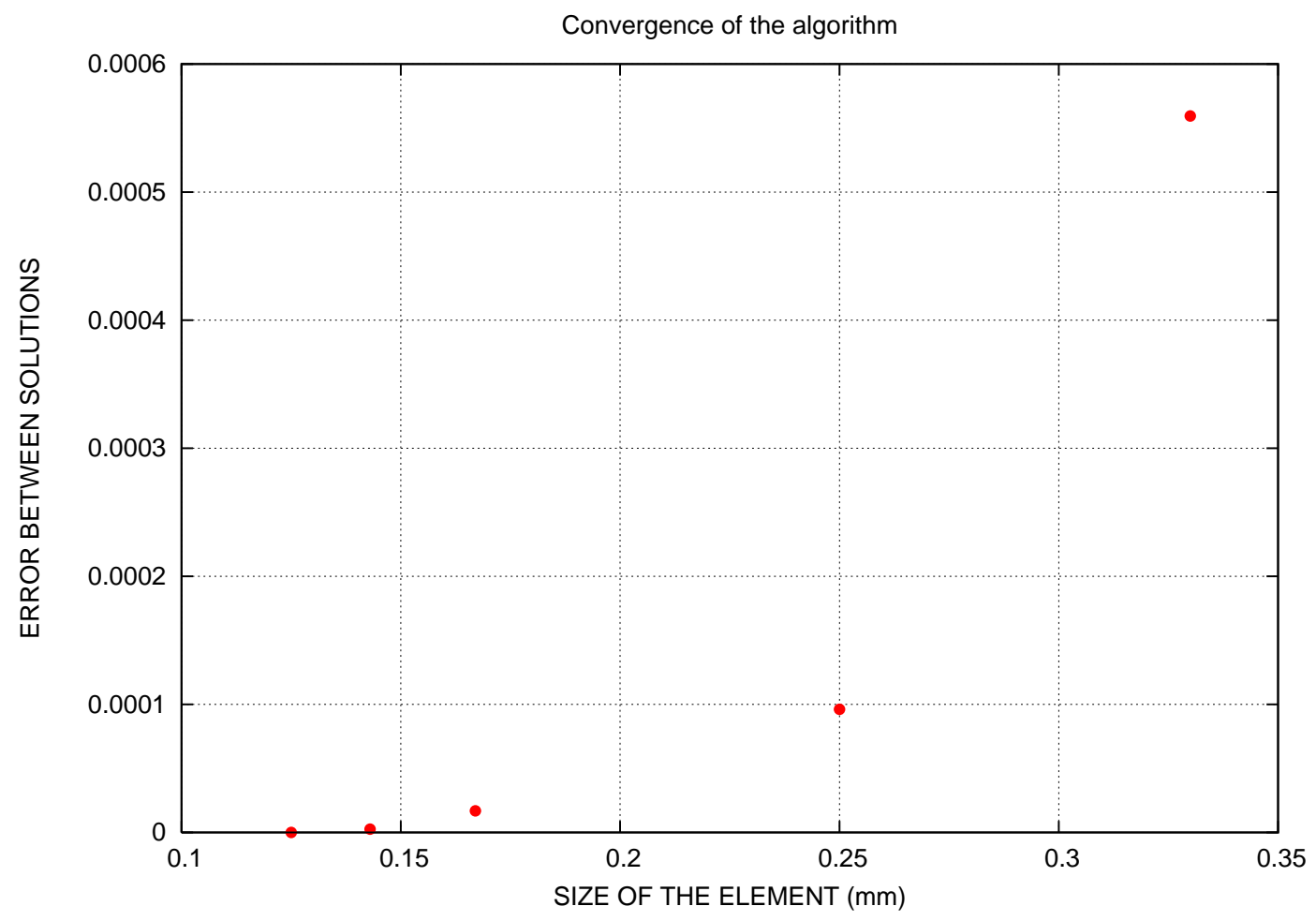

Fig. 9. Spherical case. Convergence of the algorithm 


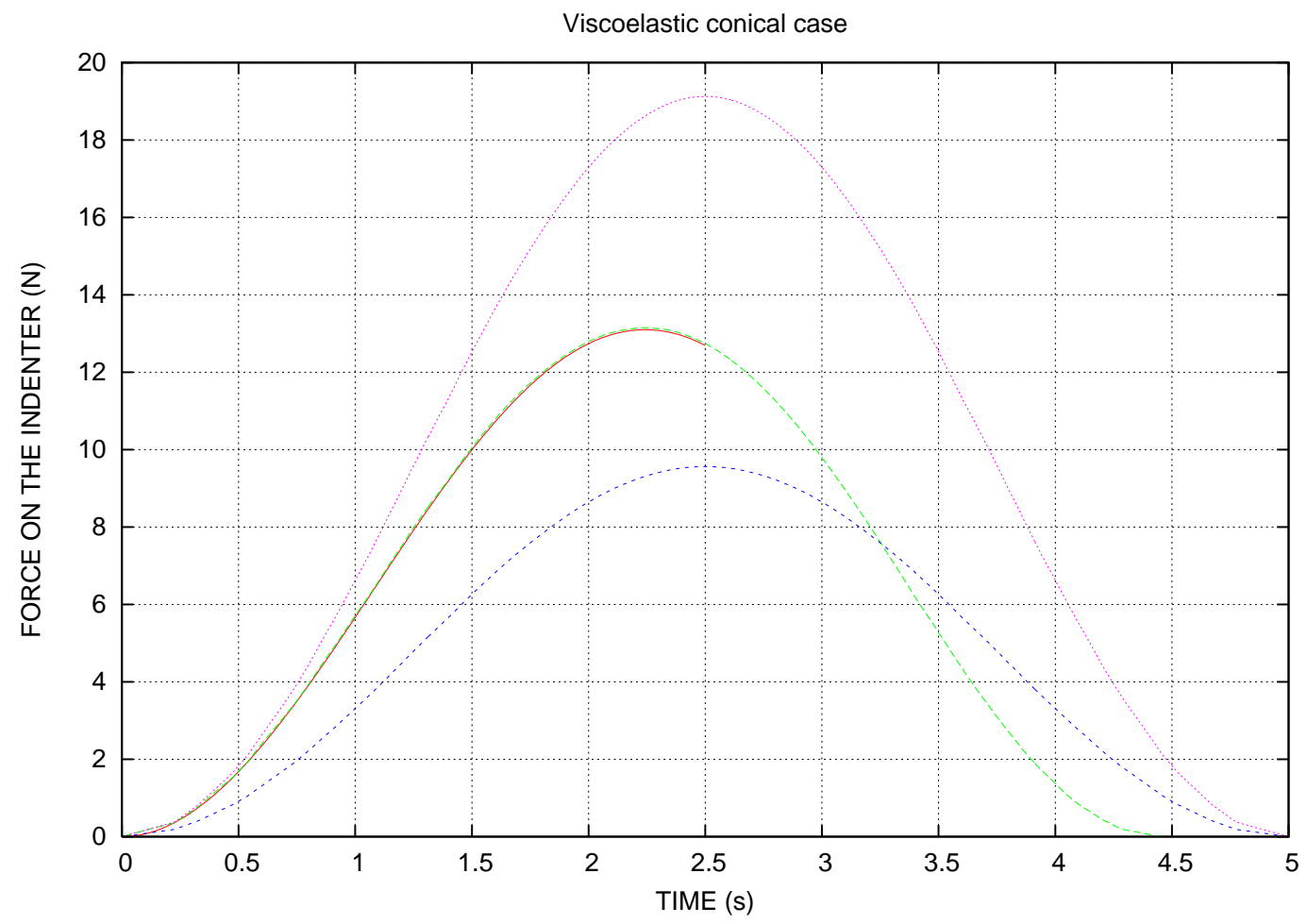

Fig. 10. Conical case. The penetration $\delta(t)$ is imposed. The difference between the contact forces, - viscoelastic analytical, ------ viscoelastic numerical, $\cdots \cdots$... elastic with $E_{\infty}=7.5 \mathrm{MPa}$, ........... elastic with $E_{0}=15 \mathrm{MPa}$ 


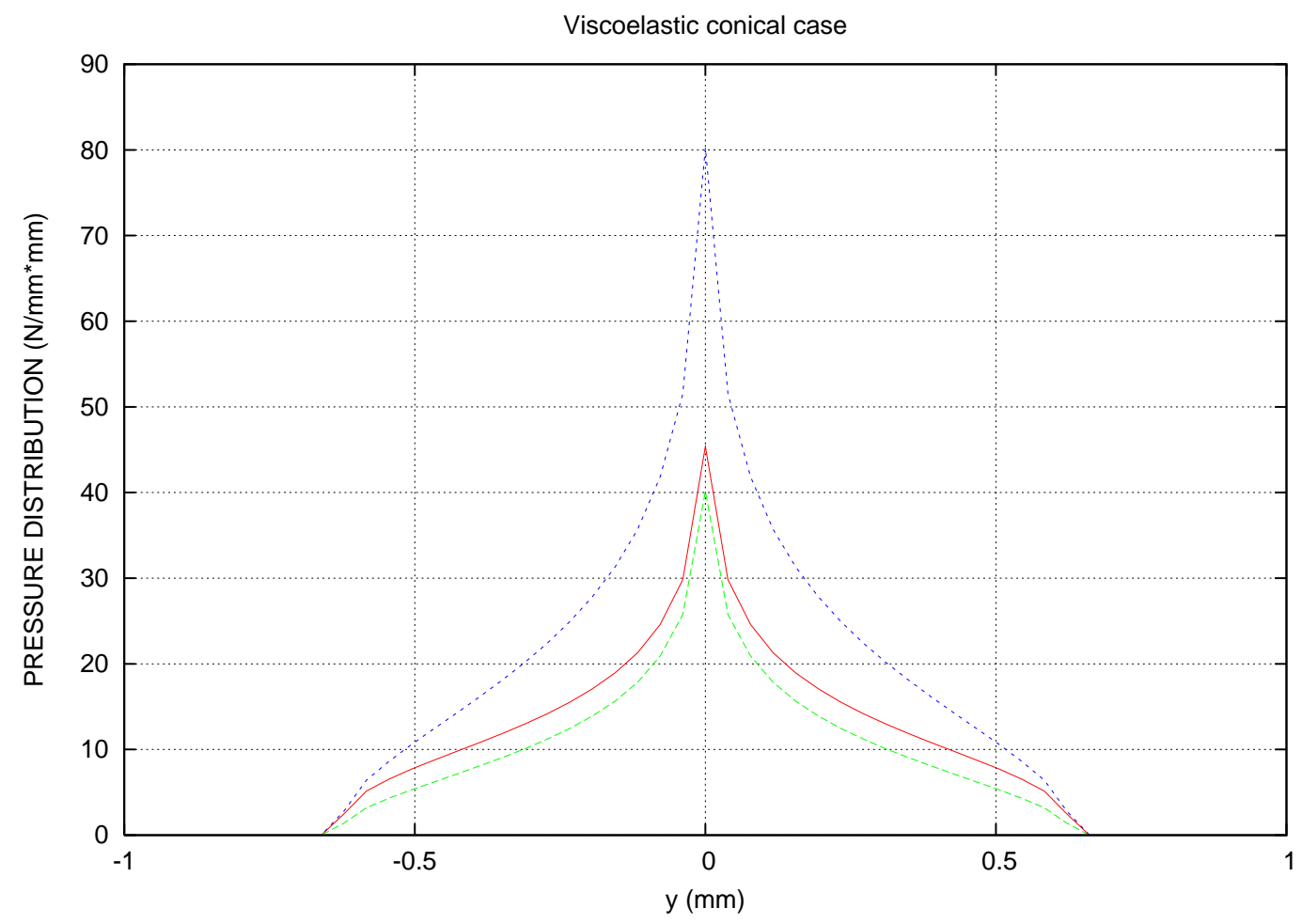

Fig. 11. Conical case. The pressure distribution for $t=2.5 \mathrm{~s}$ and $x=0 \mathrm{~mm}$, — viscoelastic numerical, ------ elastic with $E_{\infty}=7.5 \mathrm{MPa}, \cdots \cdots \cdot$ elastic with $E_{0}=15 \mathrm{MPa}$ 


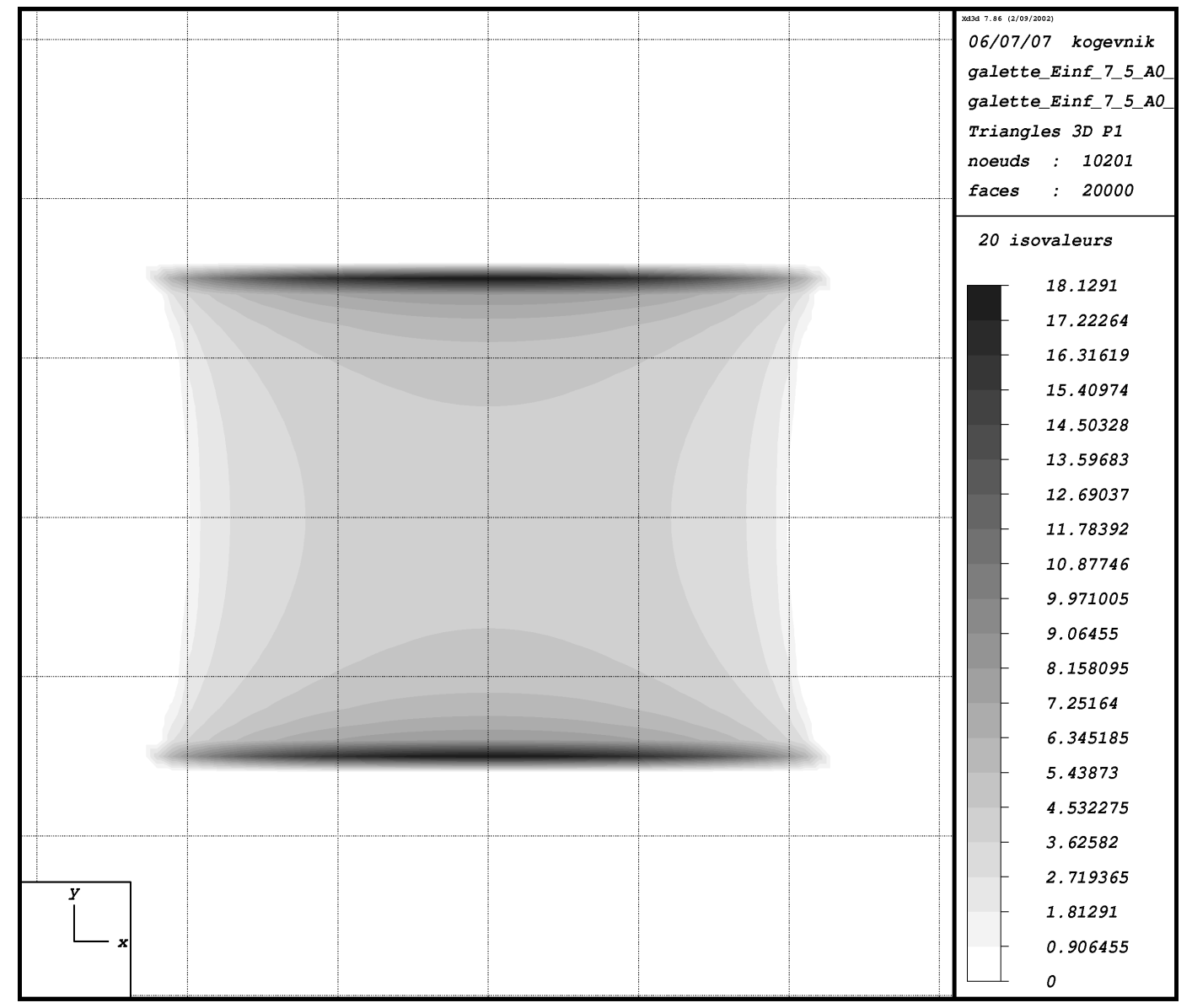

Fig. 12. Cylindrical case. The pressure distribution for $t=2.5 \mathrm{~s}$ 
(a) Viscoelastic cylindrical case

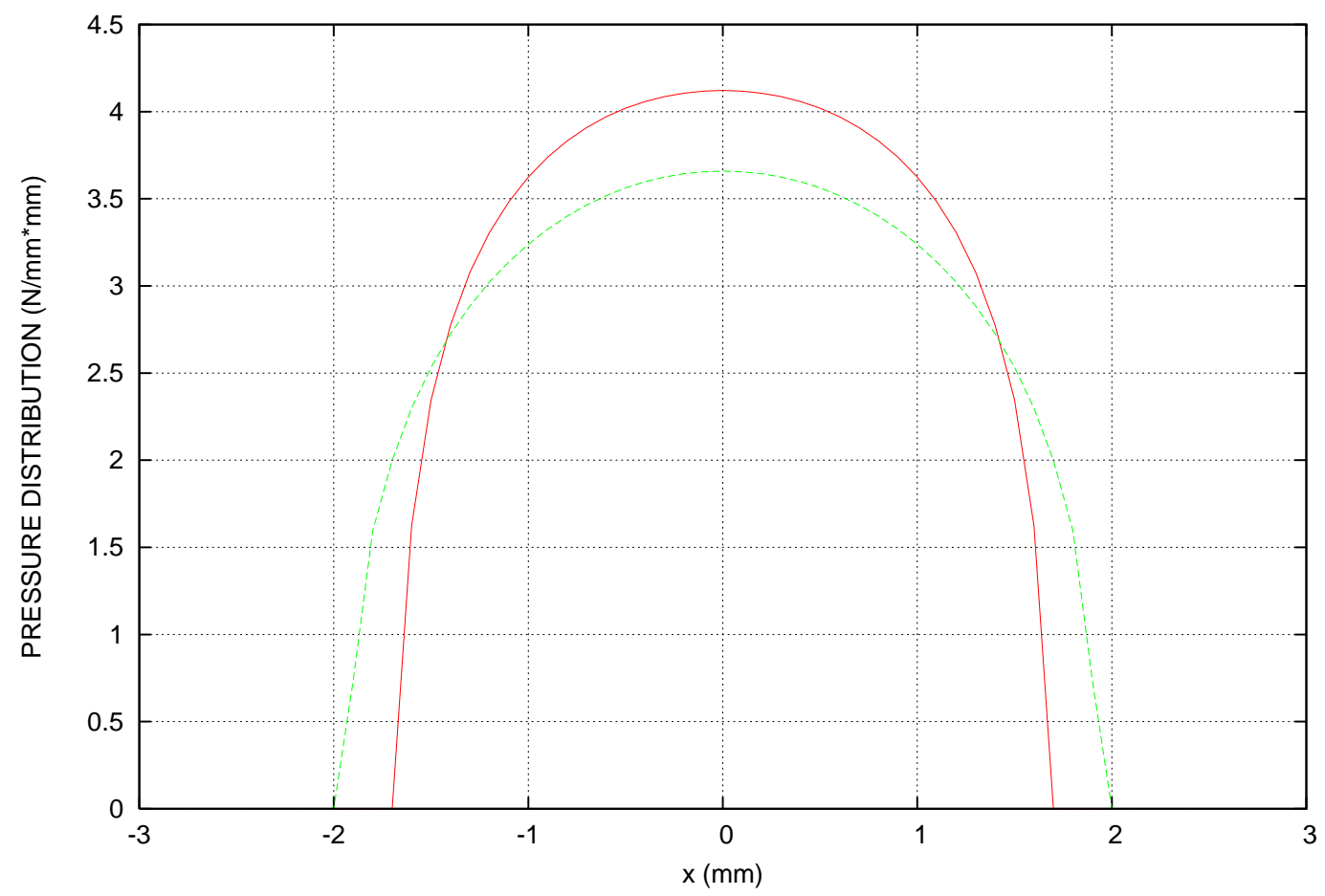

(b) Viscoelastic cylindrical case

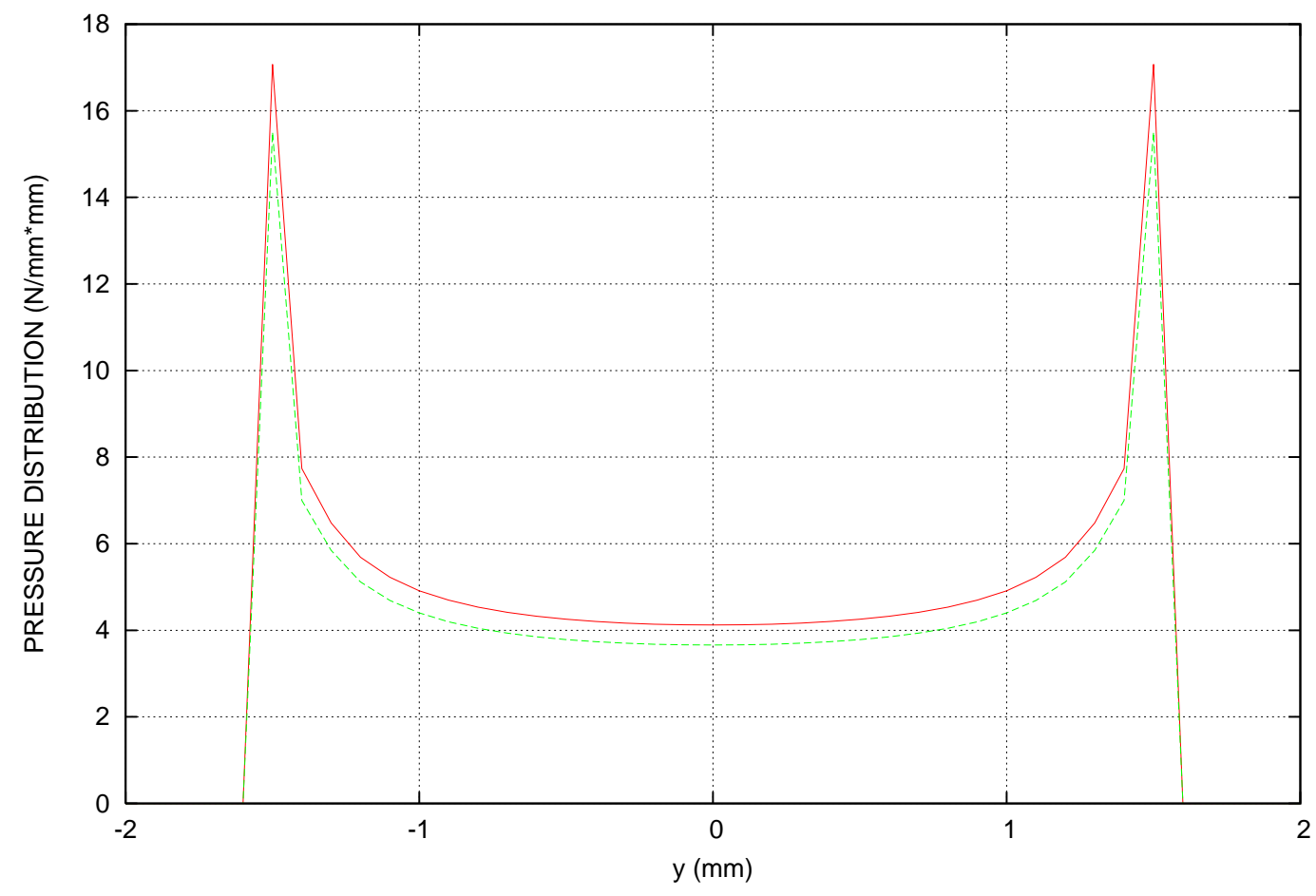

Fig. 13. Cylindrical case. The pressure distribution for $t_{1}=1.25 \mathrm{~s}$ and $t_{2}=3.05$ $\mathrm{s}(a) y=0 \mathrm{~mm},-$ viscoelastic for $t_{1}$, ------ viscoelastic for $t_{2}(b) x=0 \mathrm{~mm}$, viscoelastic for $t_{1}$,------ viscoelastic for $t_{2}$ 


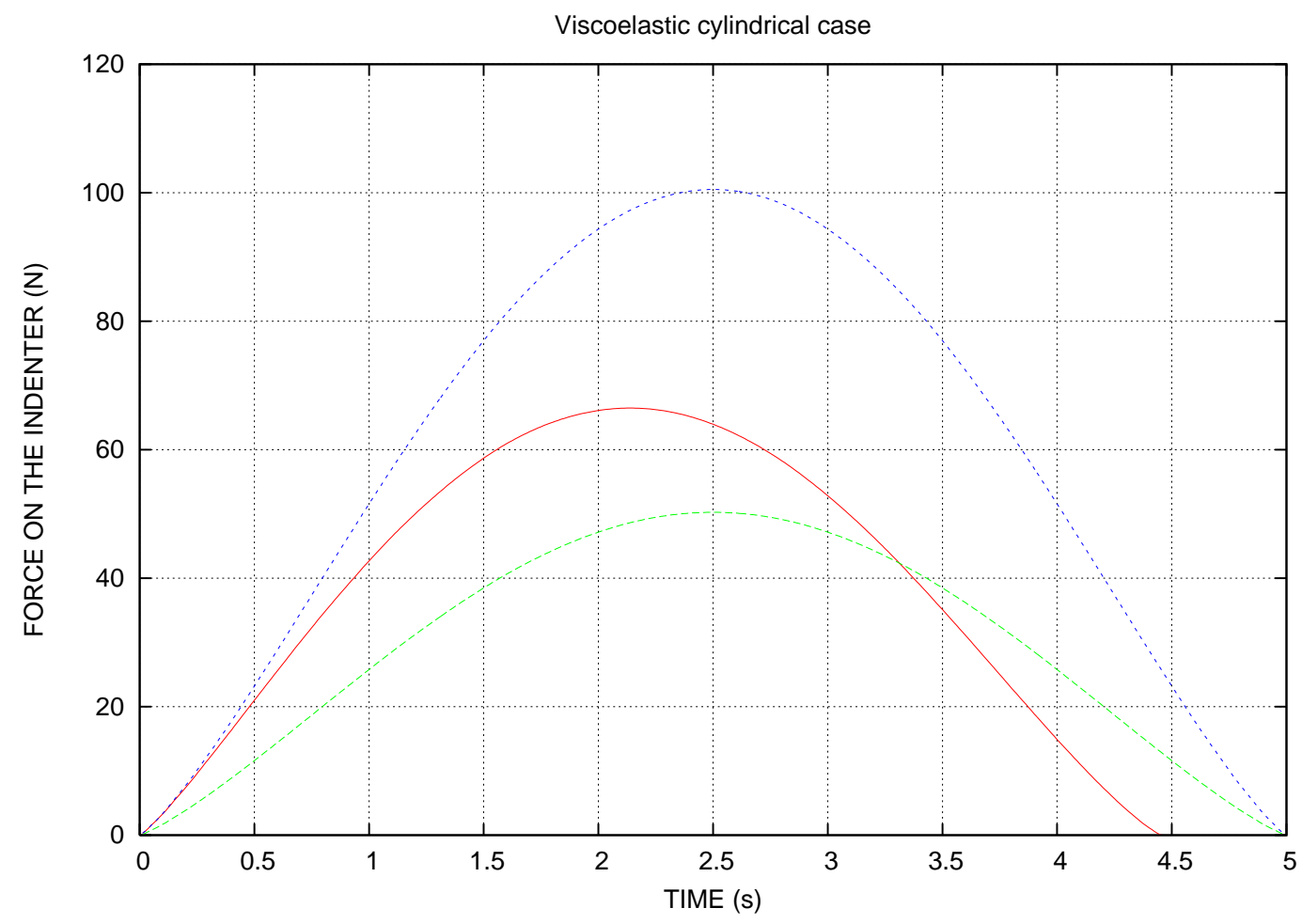

Fig. 14. Cylindrical case. The penetration $\delta(t)$ is imposed. The difference between the contact forces, - viscoelastic numerical, ------ elastic with $E_{\infty}=7.5 \mathrm{MPa}$, ...... elastic with $E_{0}=15 \mathrm{MPa}$ 


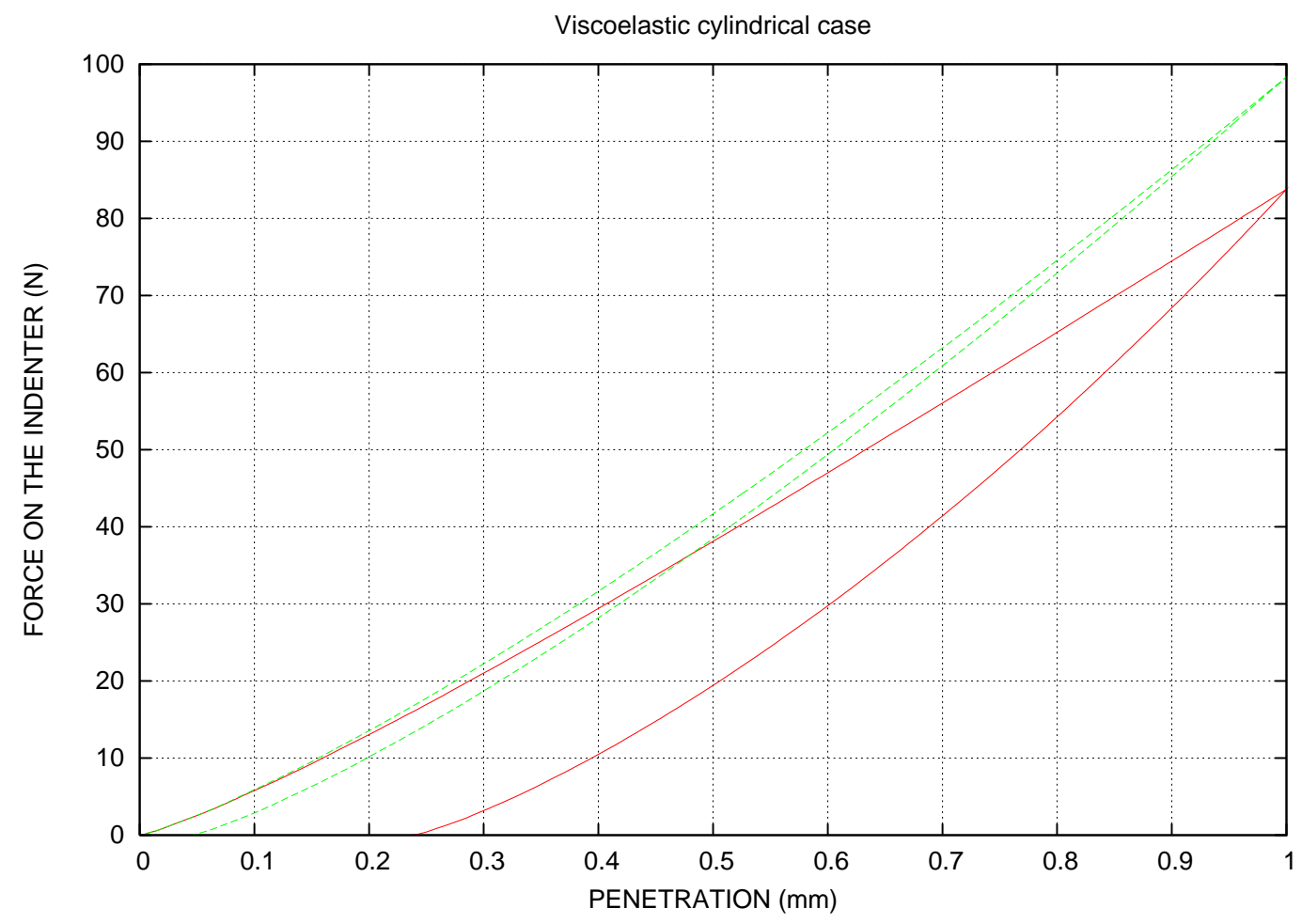

Fig. 15. Cylindrical case. The dependence of force versus the penetration $\delta(t)$ for different values of loading velocity, $-V=1 \mathrm{~mm} / \mathrm{s},------V=10 \mathrm{~mm} / \mathrm{s}$ 